Research Article

\title{
Train-Induced Fluctuating Pressure and Resultant Dynamic Response of Semienclosed Sound Barriers
}

\author{
Jing Zheng, ${ }^{1,2}$ Qingliang Li, ${ }^{3}$ Xiaozhen Li $\mathbb{D}^{1,2}$ and Yunke Luo ${ }^{1,2}$ \\ ${ }^{1}$ School of Civil Engineering, Southwest Jiaotong University, Chengdu 610031, China \\ ${ }^{2}$ MOE Key Laboratory of High-Speed Railway Engineering, Southwest Jiaotong University, Chengdu 610031, China \\ ${ }^{3}$ China Railway Eryuan Engineering Group Co. Ltd., Chongqing 400023, China
}

Correspondence should be addressed to Xiaozhen Li; xzhli@swjtu.edu.cn

Received 4 July 2019; Revised 30 July 2020; Accepted 7 September 2020; Published 22 September 2020

Academic Editor: Nuno M. Maia

Copyright ( $\odot 2020$ Jing Zheng et al. This is an open access article distributed under the Creative Commons Attribution License, which permits unrestricted use, distribution, and reproduction in any medium, provided the original work is properly cited.

This paper reports on train-induced fluctuating pressure and consequent dynamic response of semienclosed sound barriers (SESBs), a novel type of sound barriers. A computational fluid dynamic (CFD) model and a finite element (FE) model were established. The in situ vibration measurement of the SESB was introduced for the first time. Pressure-induced vibrations were extracted from the measured results. The analyzing process of the pressure-induced vibration below $20 \mathrm{~Hz}$ is verified. Influencing factors of the pressure and vibrations, including train running on the near- or far-line and the length effect of total top plates, were finally discussed with the dimensionless method. Results show that the distribution of pressure is significantly different, but the vibration laws are similar whether the train is running on the near- or far-line. The longer is the total length of the top plates, the larger are the pressure and vibration on the inner surface.

\section{Introduction}

Troubles of environmental noise and vibration triggered by rail transit have attracted a significant amount of research interests recently [1-5]. The wheel-rail noise is predominant in overall noise with the train running at a speed lower than $300 \mathrm{~km} / \mathrm{h}$ [6]. Sound barriers, which have been widely installed along trackside location all over the world, are effective in the noise reduction of rail transit by blocking direct sound propagation [7]. In China, some new-style sound barriers, such as fully enclosed or semienclosed sound barriers (SESBs), have been applied in trackside engineering to attenuate noise in some demanding regions [8]. Many research studies and exploration have been done on the acoustical performance of conventional and novel sound barriers in the available literature [9-12]; however, the studies on vibration characteristics of sound barriers, especially novel ones, were limited. The violent vibrations of sound barriers with the train speeding up, which may bring about the linked bolts falling off, structural fatigue damage, and displacement of insulation plates, may affect the safe operation of the train, result in structural noise radiation, and even reduce the noise reduction effect of sound barriers. Accordingly, correctly evaluating the vibration response of sound barrier structures is relevant for these technical issues.

If the natural wind impact is not considered, the vibration of sound barriers on high-speed railway bridges arises from wheel-rail interaction as well as aerodynamic action related to the pressure fluctuation generated by the transiting train [13]. The analysis methods to predict the wheel-rail interaction are often based on the vehicle-track dynamic coupling vibration, taking track roughness as the source of the dynamic force, considering the vehicle as a multibody system composed of carriage body, bogie, primary suspension, secondary suspension, and wheels, solving the dynamic equations of vehicles, rails, and bridges through the finite element model and dynamic theory. Li et al. solved the vibration response of track bridges in time domain by establishing the dynamic equations of vehicles, tracks, and bridges with the Newmark- $\beta$ method [14]. Wu and Thompson [15] solved the vibration response of box-girder bridges in frequency domain by the dynamic compliance 
method. For recommending the most suitable model in further prediction, Li et al. [16] compared the computation cost and accuracy of results obtained from the mode superposition method in the time domain and power flow models for the vehicle-rail-bridge coupled system are established in the frequency domain. Zhang and Xia [17] conducted dynamic analysis of the coupled vehicle-bridge system based on the intersystem iteration method. These methods all above are often applied in the vibration and vibroacoustic analysis of the coupled system. When sound barriers installed on bridges, these methods are still applicable. Li and Liang [18] investigated the influence of different track structures on the vibration and structure-borne noise of elevated concrete box girders with the frequencydomain theoretical model of the vehicle-track coupled system. Song and Li [19] compared the effects of three noise mitigation measures on noise control: installation of a noise barrier, use of a rail pad with a lower stiffness, and adopting of a floating ladder track. With the train speeding up, aerodynamic action and its resultant vibration of sound barrier cannot be ignored. Many related research studies, including basic studies aiming at the qualitative description of the pressure fluctuation, frequency-domain distribution of fluctuating wind, and pressure-induced vibration response, have been carried out. The general rules of fluctuating wind pressure versus time and its related factors were explored through scale measurements, in situ tests, and numerical simulations [20-23]. Consistent conclusions yielded from these studies are that the pressure time history curve includes the head pulse with a positive peak followed by a asymmetric negative peak appearing at the headstock passage, the small amplitude pressure fluctuation caused by the intercarriage gaps, and the tail pulse with a negative and a positive amplitude as a sequence of the tailstock passage. The peak pressure is related to train speed, vehicle type, and distance from sound barrier to the train. Yang et al. [24] decomposed the fluctuating pressure signal, collected in a field test targeting at a sound barrier, in different frequency bands, and figured out that the surface pressure component in frequency band $(0-2.5 \mathrm{~Hz})$ is large, while that in higher frequency band $(5-10 \mathrm{~Hz})$ is relatively small. Lü et al. [25] figured out that the frequency component of the aerodynamic load is less than $10 \mathrm{~Hz}$. Carassale and Marrè Brunenghi [26] carried out an open-air experiment to separate the dynamic response of the aerodynamic forces on a trackside steel frame from the effect of the seismic action caused by the train transit. According to Carassale, the head pulse and the tail pulse on the frequency map have a peak frequency of about 5.8 Hz. Luo and Zhang and Xia [27, 28] derived the calculation formulas for change of wind load acting on the car-body for a 10-span simply supported U-shaped girder bridge with $100 \mathrm{~m}$ long double-side $3.5 \mathrm{~m}$ barrier, and analyzed the influence of sudden change of wind load on the running safety of the train when a train moves into or out of the wind barrier structure.

Most of mentioned studies are aimed at some other trackside structures or sound barriers with simple structures, such as vertical sound barriers, or simple barriers with low height, whereas for semienclosed sound barriers (SESBs) with complicated structure, the train-induced fluctuating pressure and its resultant dynamic response have not been well studied.

This paper aims to bridge this gap by describing the procedures of a battery of experimental and numerical investigations carried out on a SESB arranged on a high-speed railway bridge. Firstly, train-induced fluctuating pressure and its consequent vibration were simulated numerically, and then, the vibration test of SESB is introduced. The simulated results were compared with the processed measured results for model validation. The verified models were finally applied to carry out parameter studies to investigate and discuss the influences of operating lines and total length of top unit plates on the aerodynamic pressure and dynamic response of the barrier. The results are of major importance and subsequently be used (1) to extract the pressure-induced vibration from original vibration signals according to the frequency component of fluctuating pressure; (2) to obtain the distribution law of fluctuating pressure at different locations of the SESB under different factors; and (3) to derive a fundamental understanding of the vibration response induced by fluctuating pressure of high-speed passing trains.

The composition of the SESB, the CFD model for traininduced fluctuating pressure, and the FE model for pressureinduced vibration were built, respectively, in Section 2. The setup of vibration test and main experimental results were set out in Section 3. Then, in Section 4, the CFD and FE numerical models were verified. Parameter studies were finally carried out in Section 5 to discuss the characteristics of fluctuating pressure and resultant dynamic response of the SESB.

\section{Calculating Models}

2.1. The Semienclosed Sound Barrier. The target SESB is fixed on the flanges of the $32.6 \mathrm{~m}$ long dual-track simply supported box-girder viaduct of the Hang Zhou-Changsha passenger dedicated line, China. The cross section of the barrier and the bridge girder below it are illustrated in Figure 1. The SESB is $8.15 \mathrm{~m}$ in height, $11.7 \mathrm{~m}$ in width, and $1.5 \mathrm{~km}$ in length, and its main structures with $2 \mathrm{~m}$ intervals were steel frames composed of bilateral erect steel studs and top crossbeams. To improve the stability of the steel frames, longitudinal bracings are arranged at different heights along the longitudinal direction. The main noise reduction components of the SESB are the metal sound insulation plates and transparent PC plates installed on the barrier. The steel studs and crossbeams are $\mathrm{H}$-shaped steel with a dimension of $300 \mathrm{~mm} \times 300 \mathrm{~mm} \times 10 \mathrm{~mm} \times 15 \mathrm{~mm}$. Metal plates on the closed side of the SESB, as shown in Figure 2, are $0.140 \mathrm{~m}$ thick and $0.45 \mathrm{~m}$ or $0.5 \mathrm{~m}$ wide, and the PC ones are $0.02 \mathrm{~m}$ thick and $1.1 \mathrm{~m}$ wide on the side and $1.04 \mathrm{~m}$ wide on the top. A total of 14 plates are inserted between the flange of H-type erect steel studs and stuffed rubber into interstices between the plates and the flange of H-type studs. On the top corner of SESB, a curved PC plate with $0.99 \mathrm{~m}$ radius was installed. There are 6 PC plates arranged between every two adjacent crossbeams. For further discussion, the track near the enclosed side of barrier is defined as the near-line, and on the 


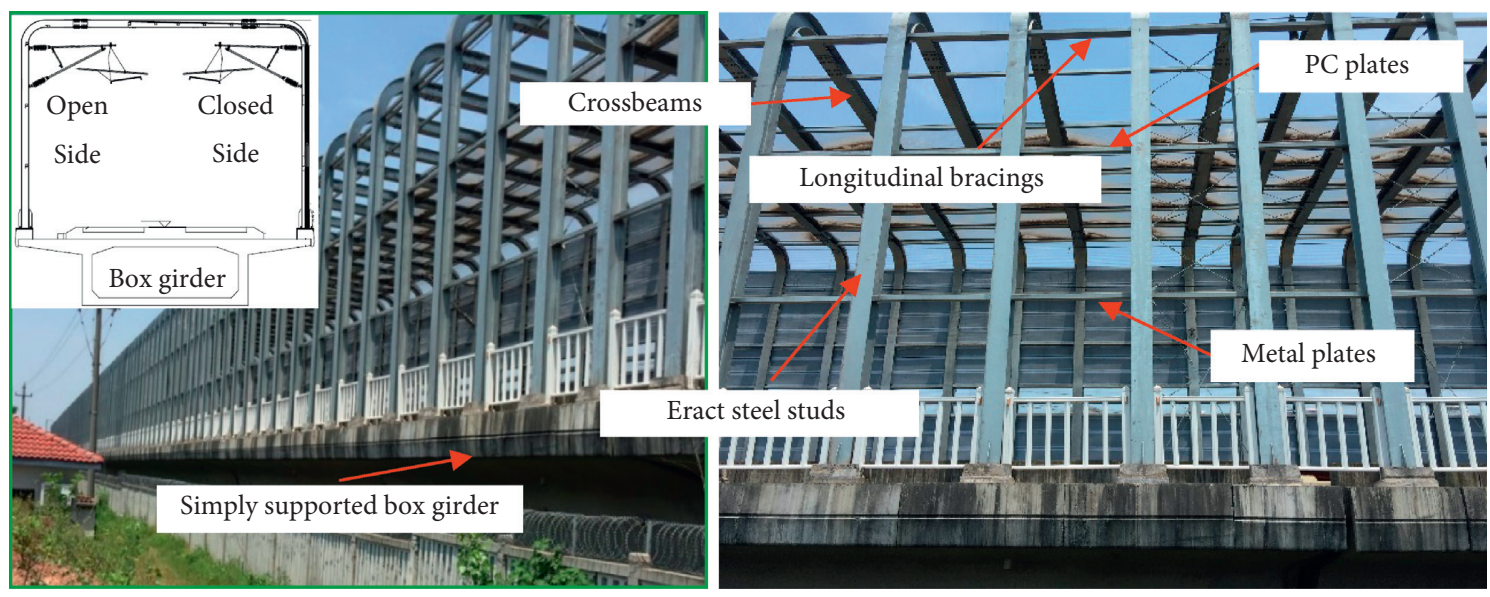

Figure 1: Target semienclosed noise barrier.

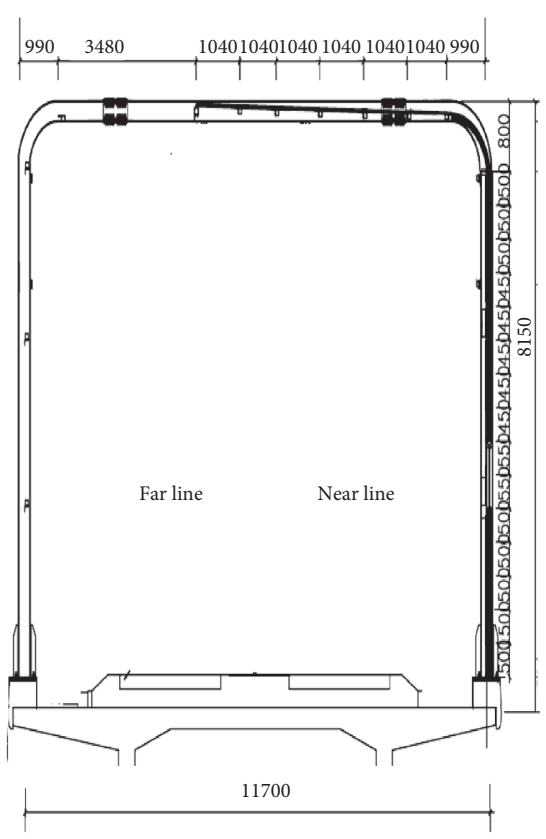

(a)

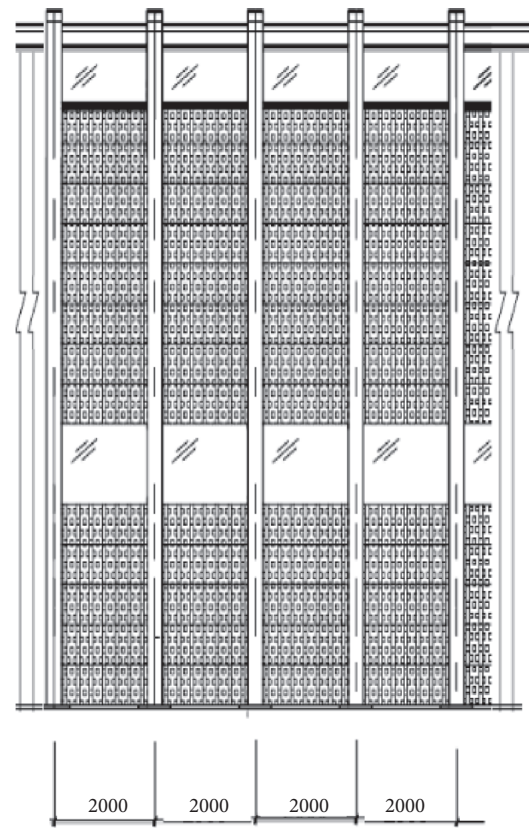

(b)

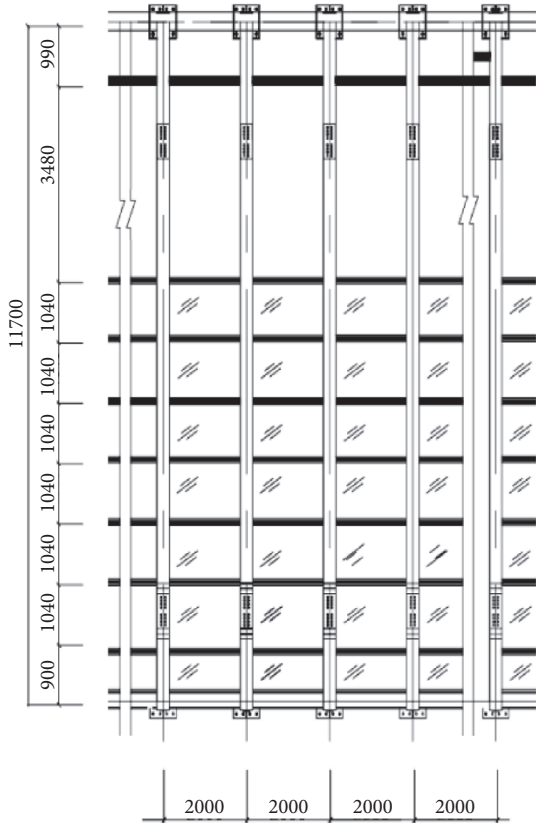

(c)

FIgURE 2: Dimensions of target semienclosed noise barrier: (a) cross section; (b) elevations; (c) top view (unit: mm).

contrary, the other one is defined as the far-line. Each two adjacent steel columns are regarded as a span of the barrier.

\subsection{CFD Model}

2.2.1. Calculation Method. When a high-speed train enters the SESB, wind fluctuating pressure will be generated. The standard $k \sim \varepsilon$ two-equation turbulent model and the threedimensional, unsteady, uncompressible RANS equation are solved by FLUENT software to simulate the train wind fluctuation on the inner surface of the SESB. In the process of establishing the CFD model, the grid model of the vehicle and SESB is firstly established (described in detail in Section 2.2.2), and then the size of the calculation domain is determined, in which the dynamic subdomain and the static regions are divided; the boundary conditions are defined.
2.2.2. Models of Train and SESB. The train model used in this paper is China Railways High-Speed 380B (CRH380B). The headstock and tailstock are $25.7 \mathrm{~m}$ long, and every midcarriage is $25 \mathrm{~m}$ long. The height and width of CRH380B are $3.89 \mathrm{~m}$ and $3.26 \mathrm{~m}$, respectively. The fluctuating pressure wave mainly consists of head pulse and tail pulse induced by the passing headstock and tailstock of the train. Therefore, the aerodynamic behavior of three car models: a lead car, a middle car, and a tail car are very similar with that of eight carriage models or sixteen carriage models. To further simplify the computational model, the train model is properly simplified: neglecting bogies, doors of the train and top pantograph, and in addition, smoothing outer surface of the train as shown in Figure 3(a).

A CFD model of the SESB was built by establishing the plates with a whole shell which is smoothed. Furthermore, 


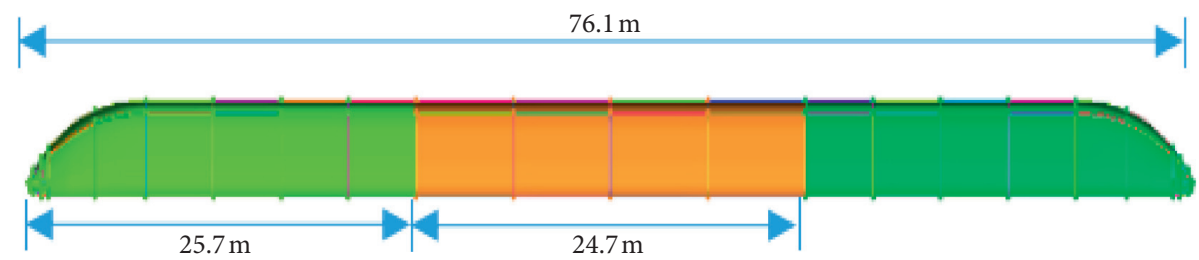

(a)

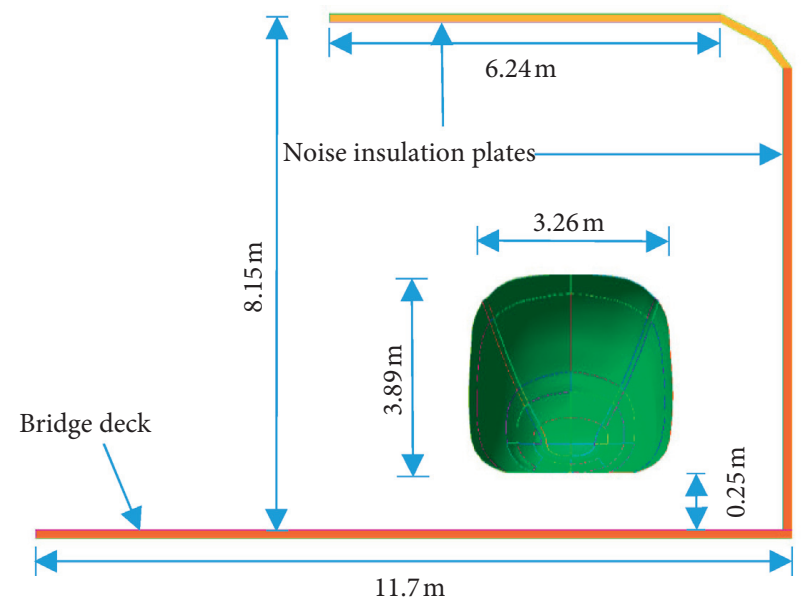

(b)

Figure 3: CFD Model of SESB: (a) simplified high-speed train model; (b) dimensions and cross section of train and noise barrier.

the components such as the track, track slab, ballast, and lower parts of the box girder were neglected in the CFD model. The simplified model of SESB is exhibited in Figure 3(b).

2.2.3. Boundary Conditions. For this model, the size of computational domain is $367.5 \mathrm{~m} \times 168.1 \mathrm{~m} \times 87.7 \mathrm{~m}$ as shown in Figure 4. In computational domain, as shown in Figure 5, the vehicle is set to be the dynamic subdomain, the sound barrier is specified to be the static regions, and the contact face is defined as an interface between the two areas. The boundary conditions of the end surfaces where air flows in and out of the computational domain are specified to be the pressure far field. For the computational accuracy and efficiency, the layering mesh method is applied in the following study. In this grid updating method, the computational domain will be divided into smaller subdomains, in which grid reconstruction is easier because of fewer grids, and the static girds at the end of the moving region will be destroyed and created to establish the expected motion of high-speed trains. When the dynamic subdomain moves forward, its front part compresses grids and the rear part stretches the grids. The grid height, 0.5 in dynamic subdomain, decides the time of grids creating and destroying, and the grid destroying coefficient is 0.2 and the grid splitting coefficient is 0.4 . The computational domain is generated totally by structured hexahedron grid. A finer grid is used in the area near the surface of the carriage and the SESB. The RANS method of wall function is used to simulate the boundary

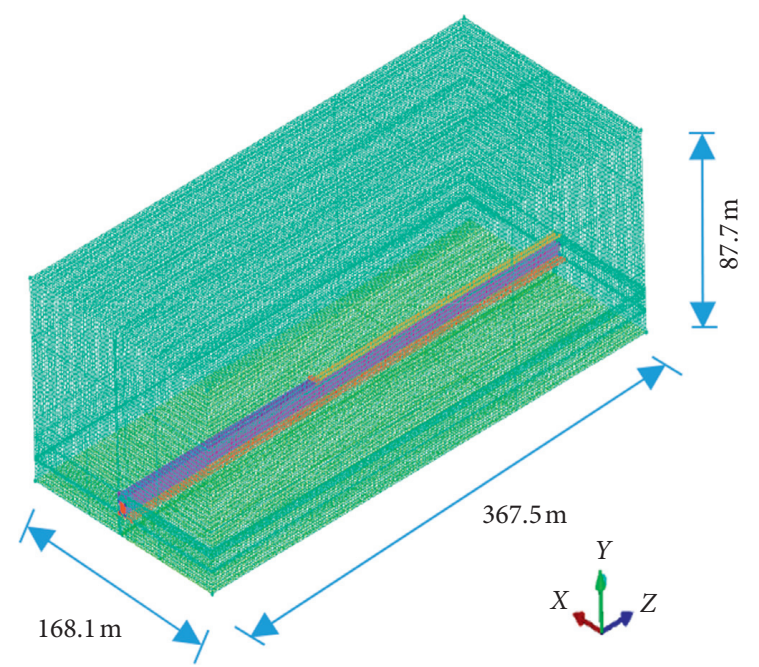

FIgURE 4: Model of high-speed train.

layer region. The thickness of finest grid on the boundary layer is $0.0012 \mathrm{~m}$. The dimensionless $y+$ for the first node from the walls is 100 , and the grid growth factor of boundary layer is 1.1. Except for the cavity of junction and endpoint, quality of the majority exceeds 0.5 . The whole model is summed up to 4.62 million nodes and 4.40 million cells. Grid independence test result shows that the average pressure on the monitoring surface obtained by further densifying the grid has little change, and the current model is accurate enough to ensure the validity of the calculated results. 


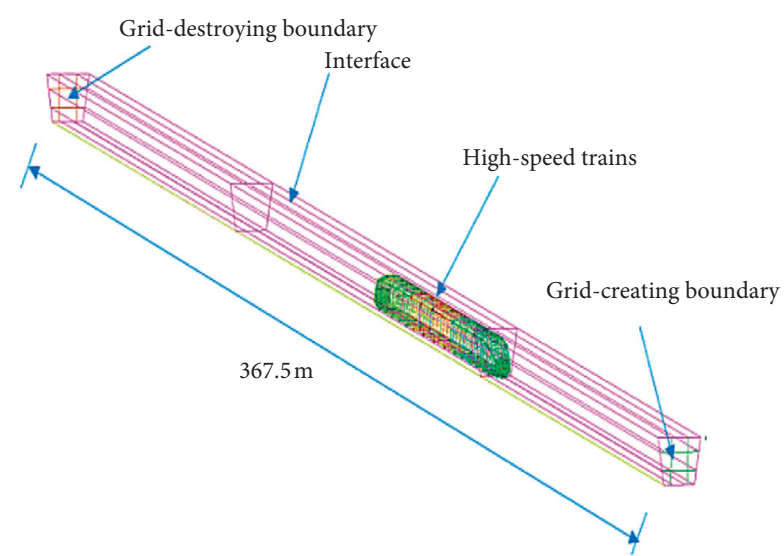

FIGURE 5: Dynamic layering region.

The initial location of high-speed train is $50 \mathrm{~m}$ away from the measured section of the barrier. The time step is $0.005 \mathrm{~s}$, and 600 steps in total are calculated. During the progress, the speed of train is set to be $330 \mathrm{~km} / \mathrm{h}$ on the near-line for the validation of the simulated model and $350 \mathrm{~km} / \mathrm{h}$ on the nearand far-line for parameter analysis. The fluctuating pressure on the inner surface of the SESB is explored by the CFD model, and the layout of monitoring faces on the SESB is shown in Figure 6 to capture their average pressure at each time step.

2.3. FE Model for Vibration Analysis. The ABAQUS software was adopted to establish the FE models of vibration responses analysis of SESB under fluctuating pressures. As the fluctuating pressure was loaded on the inner surface and box-girder bridge was not subjected to this load, concrete bases under the steel studs, instead of the box-girder bridge, were established as the foundation of SESB and were modelled with eight-node 3D brick elements (C3D8R). The roots of steel studs were fixed on the concrete bases. Steel studs were modelled with four-node shell elements (S4R), as well as the crossbeams and the plates. As the fluctuating pressure-induced vibration is mainly consisted of low-frequency one, the rubbers stuffed between every two adjacent plates and in the interspaces from plates to steel studs can be omitted because the rubber damping pads can hardly damp vibration of low frequency. The total FE model is shown in Figure 7(a), and its size is consistent with design drawings of SESB. The calculated pressure is expanded from the CFD simulated results of the middle carriage to the pressure of the middle six carriages, they are combined with the head and tail pulse to form the pressure of the eight marshalled train, and they are applied to all the plates in a span on the SESB according to Figure 6. Fluctuating pressure is also applied to the plates on adjacent spans considering the time interval of trains passing through different spans of the SESB. The instantaneous vibration responses such as the dynamic displacement of SESB under pressure can be solved. In Section 4, the calculated results will be compared with the measured ones to verify the applicability of the CFD model and FE model.

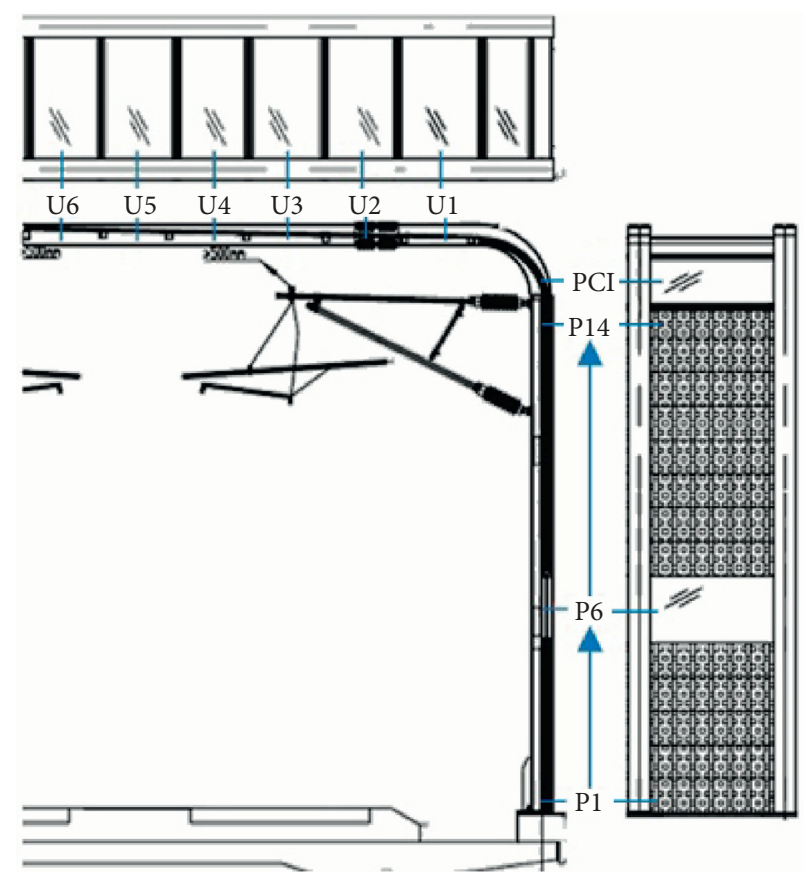

FIgURE 6: Layout of monitoring faces on the surface of SESB.

Table 1 tabulates all the material properties of this model. Figures $7(\mathrm{~b})$ and $7(\mathrm{c})$ present the typical modal vibration shape of SESB, and the first 10 modes of natural frequencies are listed in Table 2. The first mode showing transverse deformation of the SESB is at $4 \mathrm{~Hz}$, and the vertical bending mode is above $5.45 \mathrm{~Hz}$. Whether pressure-induced resonance occurs will be analyzed in Section 3.2.

\section{Schemed Field Test}

3.1. Testing Instrumentation. A field test was conducted to obtain the vibration response of the target SESB. During the test, three variables were continuously recorded: the train speeds, the location of the moving train, vibration acceleration orthogonal to the test surface by means of a velocimeter, 5 accelerometers and a dynamic data acquisition instrument. Additional information is given below on the location and installation of the monitoring systems.

3.1.1. Accelerometers. The CA-YD-181 piezoelectric type accelerometers were used to collect the vibration signals. A total of about 5 accelerometers were monitored on the barrier at the midspan of the bridge. Accelerometers were installed through a moving crane as shown in Figures 8(a) and 8(b), which display the distribution and specific locations of accelerometers. $V 1$ and $V 2$ were arranged on the steel stud of the closed side of the SESB at $7.3 \mathrm{~m}$ and $1.5 \mathrm{~m}$ high from the root, respectively, which were the same height with the top of No.13 plate and No. 3 plate, respectively. V3, $V 4$, and $V 5$ were measuring points on the open side, which were located at $7.3 \mathrm{~m}, 5.8 \mathrm{~m}$, and $4.45 \mathrm{~m}$ high from the root of noise barrier, respectively, the same height with the top of No. 13, No. 10, and No. 7 plate, respectively. 


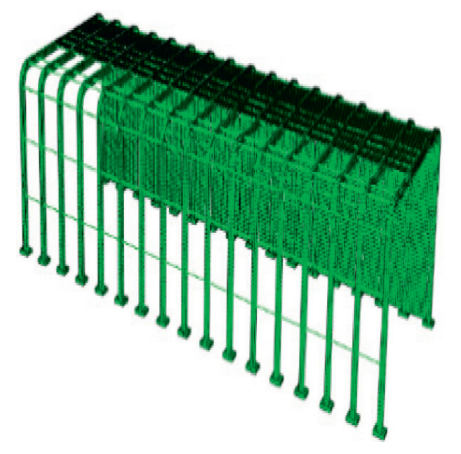

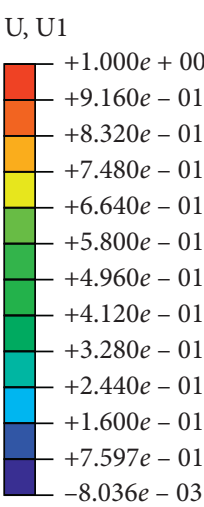

(a)

$\mathrm{U}, \mathrm{U} 3$
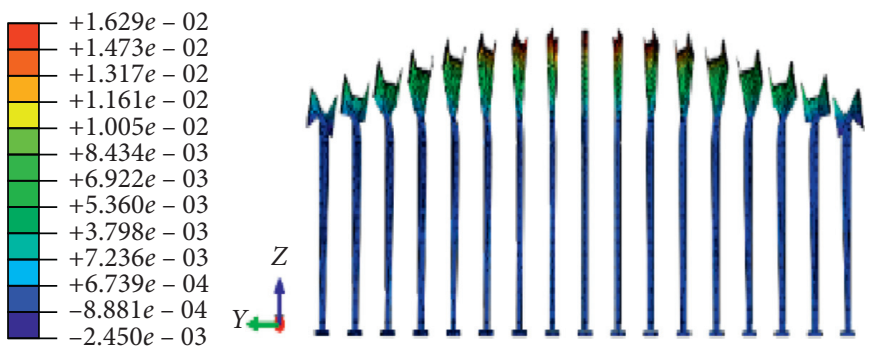

(c)

FIGURE 7: FE model of the SESB and typical modal vibration shape: (a) finite element model; (b) the first transverse bending (4.00 Hz); (c) the first vertical bending $(5.45 \mathrm{~Hz})$.

TABLE 1: Material properties of SESB.

\begin{tabular}{lcccc}
\hline Material & $\mathrm{E}\left(\mathrm{N} / \mathrm{m}^{2}\right)$ & $\begin{array}{c}\text { Poisson } \\
\text { ratio }\end{array}$ & $\begin{array}{c}\text { Density } \\
\left(\mathrm{kg} / \mathrm{m}^{3}\right)\end{array}$ & $\begin{array}{c}\text { Damping } \\
\text { ratio }\end{array}$ \\
\hline Steel & $2.06 \times 10^{11}$ & 0.3 & 7850 & 0.010 \\
Concrete & $3.25 \times 10^{10}$ & 0.2 & 2400 & 0.030 \\
PC & $2.32 \times 10^{9}$ & 0.4 & 1200 & 0.200 \\
Aluminum & $7.2 \times 10^{10}$ & 0.3 & 2670 & 0.010 \\
\hline
\end{tabular}

TABLE 2: The first 10 modes of natural frequencies.

\begin{tabular}{lccc}
\hline Mode & Frequency $(\mathrm{Hz})$ & Mode & Frequency $(\mathrm{Hz})$ \\
\hline $1^{\text {st }}$ & 3.25 & 6 th & 4.56 \\
$2 \mathrm{ed}$ & 3.74 & 7 th & 4.63 \\
3 th & 4.00 & 8 th & 4.68 \\
$4^{\text {th }}$ & 4.27 & 9 th & 4.71 \\
$5^{\text {th }}$ & 4.46 & 10 th & 4.75 \\
\hline
\end{tabular}

3.1.2. Train in Field Test. The field test was carried out with a high-speed passing train of CRH380 B. The speed of the train passing through the test section is relatively stable. The traininduced vibration of the SESB is more intensive when the train speed is high enough.

3.1.3. Data Recording System. INV3060S dynamic data acquisition instrument was adopted to collect the vibration information, and the sampling frequency was $25.6 \mathrm{kHz}$. More than 20 sets of data were monitored on the open side and the closed side, among which 7 sets are about passing train speed around $330 \mathrm{~km} / \mathrm{h}$ on near-line. Preliminary analysis is carried out to eliminate abnormal data before data processing, and then, statistical average is made on the 7 sets of valid data.

\subsection{Testing Results}

3.2.1. Measured Results in Time Domain. Now, that the frequency components of fluctuating pressure are different from wheel/rail interaction, the measured vibration signals could be processed by $20 \mathrm{~Hz}$ low-pass filtering to obtain lowfrequency vibration induced by the pressure. Figure 9 manifests the filtered results at monitoring points $V 1-V 5$ on the SESB in time domain.

The pressure-induced vibration of all measuring points $V 1-V 5$ on the closed side of the SESB is shown in Figures 9(a)-9(d). It indicates that all the waveforms show the similar characteristics with the train-induced pulse. For $V 2$ on the bottom, the vibration response is relatively less than $V 1$, and measured peak accelerations of $V 1$ and $V 2$ are $2.5 \mathrm{~m} / \mathrm{s}^{2}$ and $0.7 \mathrm{~m} / \mathrm{s}^{2}$, respectively. As shown in Figures 9(c)-9(d), the peak accelerations are $2.6 \mathrm{~m} / \mathrm{s}^{2}$, $2.2 \mathrm{~m} / \mathrm{s}^{2}$, and $1.6 \mathrm{~m} / \mathrm{s}^{2}$ for $V 3, V 4$, and $V 5$, respectively. The vibration on the upper part $(V 1$ and $V 3)$ is larger.

3.2.2. Measured Results in Frequency Domain. The measured results from the field test in Figure 9 are transformed into the frequency domain. Because the fluctuating pressure 


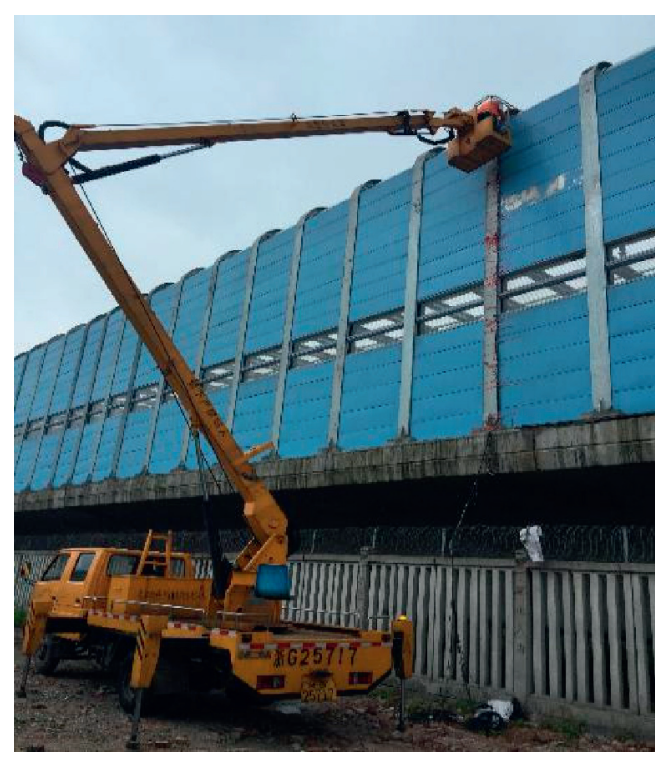

(a)

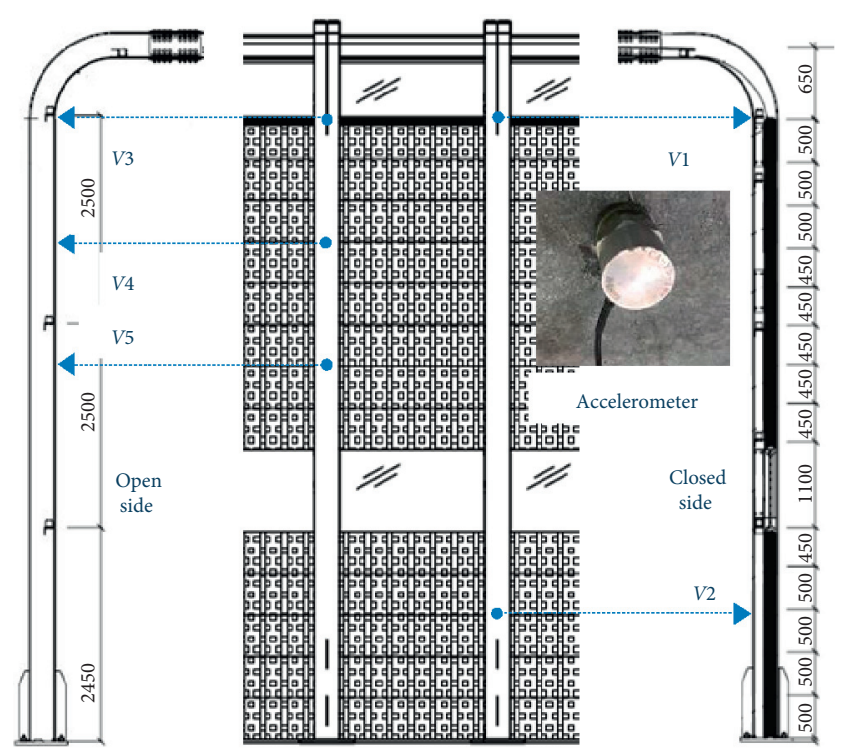

(b)

FIGURE 8: Arrangement of accelerometer: (a) photo of accelerometer arranging; (b) accelerometer distribution on the SESB.

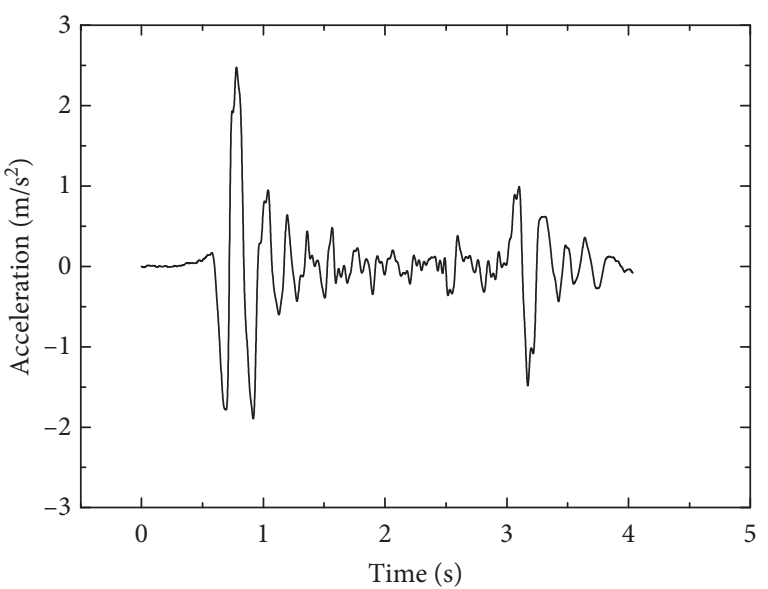

(a)

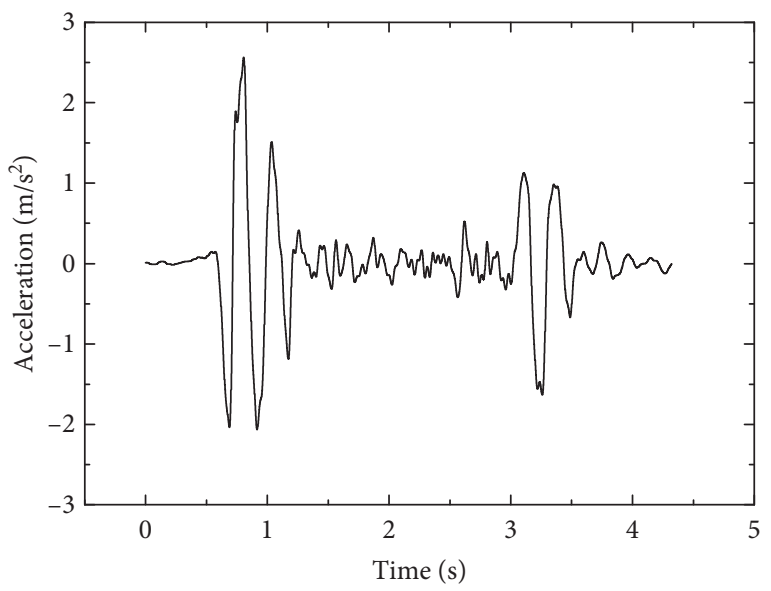

(c)

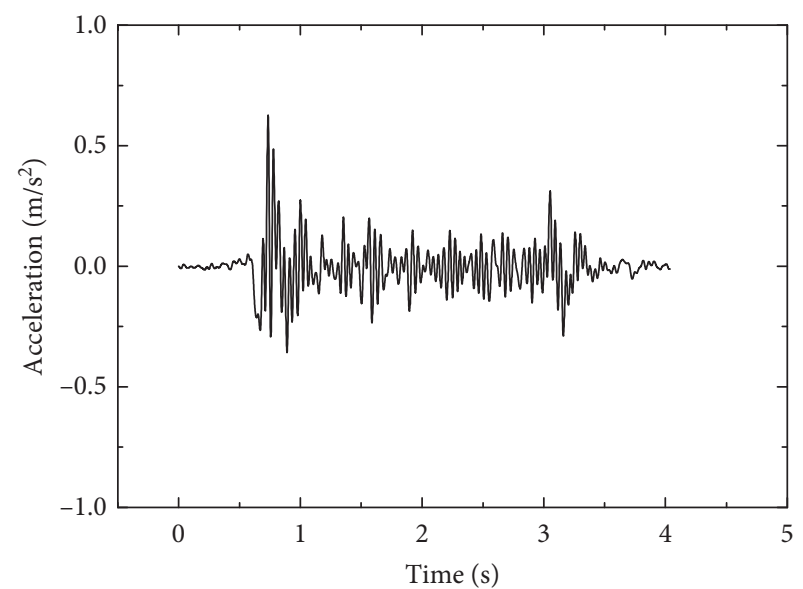

(b)

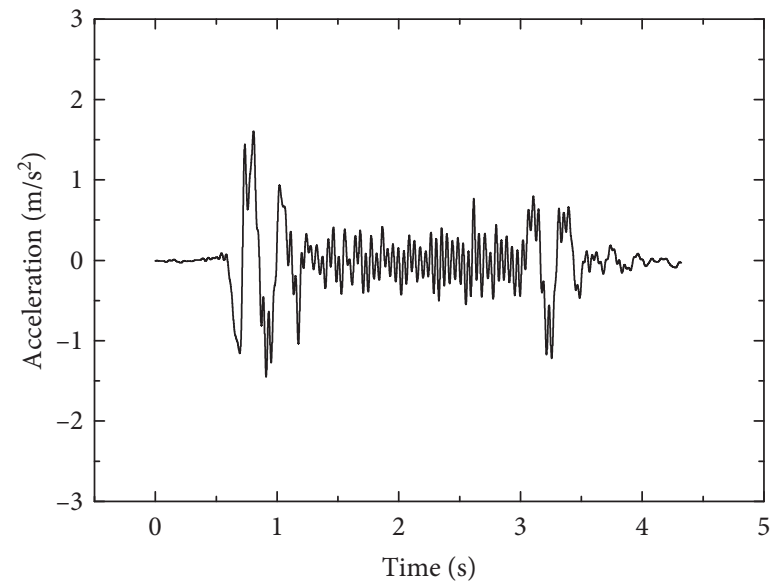

(d)

FIgURE 9: Measured acceleration time histories of SESB: (a) V1; (b) V2; (c) V3; (d) V5. 
mainly acts within low-frequency range, Figure 10 only shows the acceleration spectra below $20 \mathrm{~Hz}$. It is indicated that the recorded peak acceleration induced by the pressure is about $0.78 \mathrm{~m} / \mathrm{s}^{2}$ at $6.8 \mathrm{~Hz}$ when the train is on the near-line and is about $0.61 \mathrm{~m} / \mathrm{s}^{2}$ at $3.3 \mathrm{~Hz}$ when the train is on the farline. Compared to the calculated natural frequency exhibited in Table 2, the frequency components of the SESB under the fluctuating pressure are different from the transverse mode at $4 \mathrm{~Hz}$, although many small peaks appear in the acceleration spectra. It can be inferred that the SESB could not resonate with the train-induced pressure. Further investigation should be invested for fatigue issues of the SESB combined with the pressure-induced strains, but these issues are not discussed in this article.

The vibration acceleration from perceptible acceleration (about $10^{-3} \mathrm{~m} / \mathrm{s}^{2}$ ) to intolerable acceleration (about $10^{3} \mathrm{~m} / \mathrm{s}^{2}$ ) for the human body changes up to 1 million times. The vibration acceleration level (VAL) is hence adopted to judge the vibration intensity of the SESB according to Chinese railway industry standard: measurement of railway environmental vibration (TB/T: 3152-2007), and it could be calculated by the following formula:

$$
\mathrm{VAL}=20 \lg \left(\frac{a_{\mathrm{rms}}}{a_{\mathrm{ref}}}\right)
$$

where VAL is vibration acceleration level; $a_{\mathrm{rms}}$ is the virtual value of acceleration $\left(\mathrm{m} / \mathrm{s}^{2}\right)$; and $a_{\text {ref }}=10^{-6} \mathrm{~m} / \mathrm{s}^{2}$ is reference acceleration. In addition,

$$
a_{\mathrm{rms}}=\sqrt{\frac{1}{T} \int_{0}^{T} a^{2}(t) \mathrm{d} t}
$$

where $T$ is analysis time and $a(t)$ is vibration acceleration at $\mathrm{t}$ time.

The vibration is also presented by the way of one-third octave spectra to show the overall trends in the frequency domain, because there are many peaks with different frequency components in the spectra as shown in Figure 10, some of which cannot be reproduced through the simplified numerical calculation, and the vibration trend of each measuring point is not easy to distinguish. Figure 11 illustrates the measured VAL spectra curves of measuring points $V 1 \sim V 5$ from $1 \sim 20 \mathrm{~Hz}$ by one-third octave spectra. For $V 1, V 3, V 4$, and $V 5$ on upper and middle parts of SESB, their vibration characteristics are similar to each other, with dominant frequency range of $2.5 \sim 5 \mathrm{~Hz}$. This is due to the action of fluctuating wind and the vibration characteristics of sound barrier. While for V2 located at barrier's lowest part, its vibration peak is relatively smaller and occurred at the frequency band of $10 \sim 20 \mathrm{~Hz}$, where low-frequency wheel/rail interactions gradually become the main excitations of vibration. However, the pressure action is still dominant within frequency range of $2.5 \sim 5 \mathrm{~Hz}$.

\section{Validation Study}

Firstly, the CFD numerical method in this paper is verified by the fluctuating wind pressure on the surface of the semicovered snow barrier along the high-speed railway line

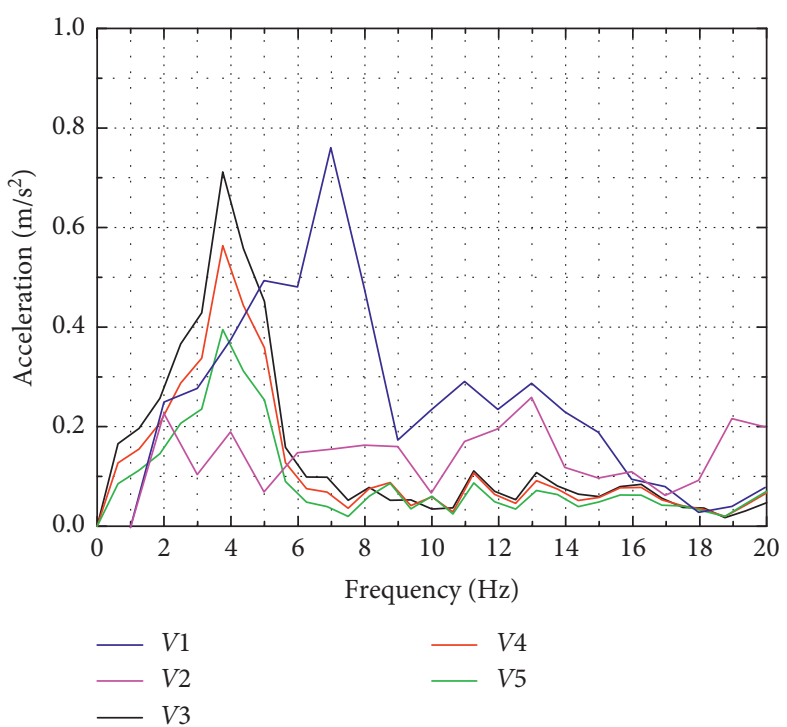

FIGURE 10: Spectra of measurement acceleration.

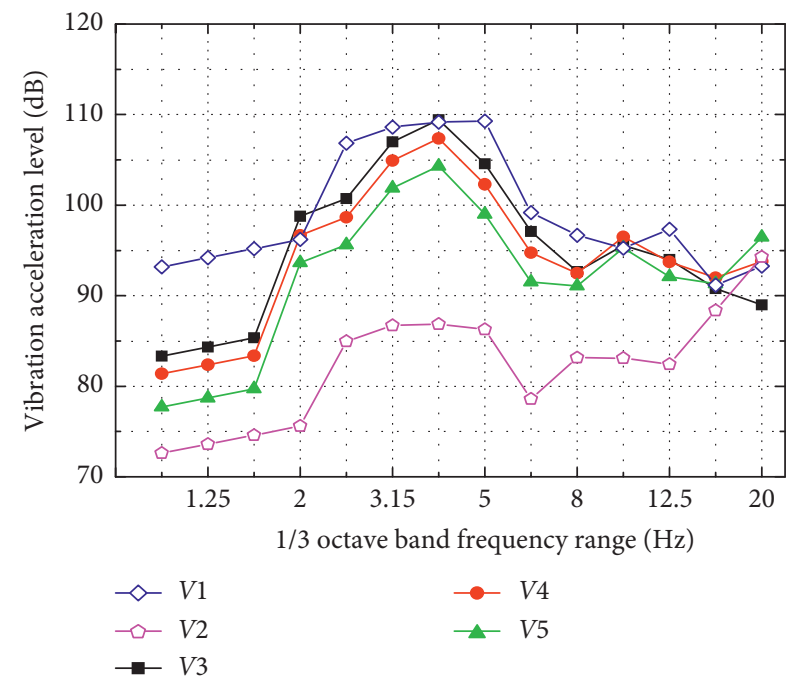

FIgURE 11: Measured vibration acceleration level spectrum of SESB.

generated by train traffic in reference [29]. The corresponding model is established by using the same modelling method and parameter values in Section 2.2 of this paper. The comparison between the measured results and the simulation ones at the speed of $252 \mathrm{~km} / \mathrm{h}$ is shown in Figure 12. It can be seen that the time history law of the simulated pressure is consistent with the measured one. The "head wave" generates when the head carriage passes through the measurement section, and the "wake wave" generates when the tail carriage passes. The peak pressure of wake wave is about $50 \%-80 \%$ of that of head wave. The peak value of head wave negative pressure and tail wave positive pressure obtained by numerical simulation is slightly larger than the measured value, mainly due to the vehicle model which is Japanese high-speed train, and different from CRH380 B. The simulated results are essentially in agreement with the measured ones, so that the CFD model in this 


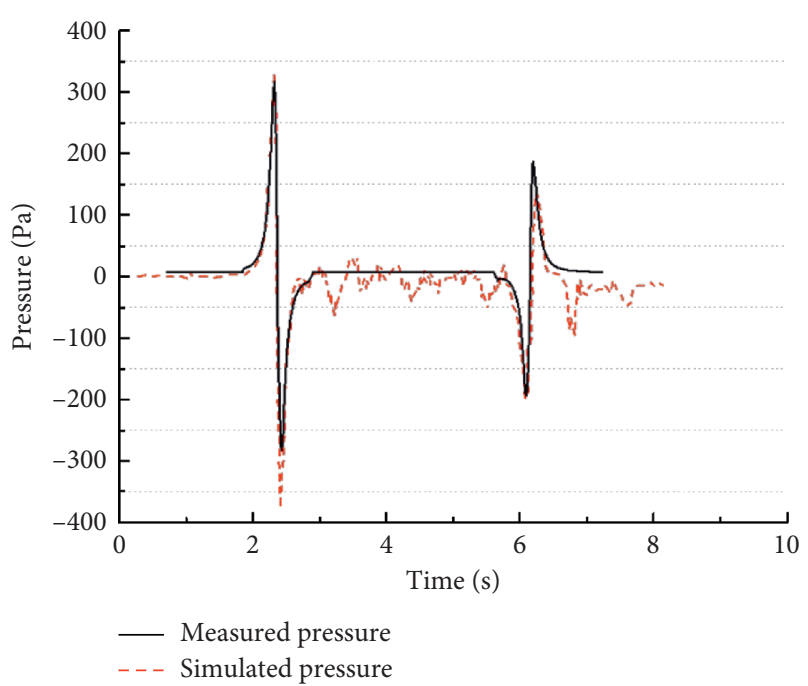

FIGURE 12: Comparisons of the simulated train-induced fluctuating pressure.

paper can accurately simulate the fluctuating wind pressure caused by the passing trains.

The dynamic displacement from FE results introduced in Section 2.3 is transformed into the dynamic acceleration in time domain by second derivative, and then, the dynamic acceleration in frequency domain is formed by fast Fourier transform. Finally, the VALs in $1 / 3$ octave frequency band are calculated according to formula (1) and (2). To validate the accuracy of numerical models, the processed simulated results are compared with the measured vibration acceleration in time domain and the VALs in frequency domain.

Figure 13 compares the simulated and filtered measured vibration acceleration in time domain of measuring points $V 1$ and $V 2$ on the enclosed side. The simulated accelerations are in accordance with measured ones, and the waveforms of both curves are consistent with the train-induced fluctuating pressure. However, the measured accelerations, especially for the lowest measuring point $V 2$, have some higher frequency components when the intermediate section of a train passing by. This may be both due to the wheel-rail interactions the lower parts of SESB suffer more below $20 \mathrm{~Hz}$, and due to the aerodynamic force induced by the intercarriage discontinuities in low-frequency, which cannot be reproduced by the CFD model. The maximum vibrations of the SESB in low-frequency component are caused by the head and tail pulse of fluctuating pressure, and the vibration time history obtained by filtering can reflect the dynamic characteristics of the fluctuating wind, which ensure that the $20 \mathrm{~Hz}$ low-pass filtering is effective enough in reflecting the pressure-induced vibration.

Figure 14 exhibits the one-third octave of VAL of measuring points $V 1$ and $V 2$ (enclosed side) and $V 3$ and $V 5$ (open side) derived from the numerical models and filtered measured results. It can be seen that the simulated characteristics of all points are consistent with the measured ones in $1 \sim 10 \mathrm{~Hz}$ frequency range, with peak value at $4 \mathrm{~Hz}$, and the measured results are slightly larger than the simulated ones due to the remained low-frequency wheel/rail forces. In
$10 \sim 20 \mathrm{~Hz}$ frequency range, the simulated results are not that consistent with the measured ones. This is because the traininduced pressure attenuates in this frequency range and the wheel/rail forces gradually become the main excitations for the vibration of the SESB.

It can also be proved that the vibration accelerations on the open side are consistent with the measured results $(V 3-V 5)$ in time domain and frequency domain. So far, it can be concluded from above comparison that the fluctuating pressure is the main excitation of vibration in frequency range 1 20 Hz. Both the calculated acceleration time histories and the $V A L$ spectra of vibration are in accordance with the measured ones and it is not worth bothering to take wheel/rail forces into account when analyzing the characteristics of vibration under pressure. Therefore, the present numerical models are able to reproduce the fluctuating pressure and the resultant dynamic response of the SESB with sufficient accuracy and are can be used for further discussions.

\section{Discussion}

Based on the calibrated CFD and FE models of aerodynamic pressure and vibration of SESB, the characteristics of aerodynamic pressure and dynamic response under different factors are investigated in this section. Two influential factors, operation line and number of top SIP, are discussed. Train speed is uniformly set as $350 \mathrm{~km} / \mathrm{h}$ for parameter studies. In order to generalize the results, the response quantities in the following test, including the time and the fluctuating pressure are dimensionless using the train velocity according to the following formulas:

$$
\begin{gathered}
\mathrm{T}=\frac{t V_{\text {train }}}{L}, \\
C_{P}=\frac{P(T)-P_{0}}{0.5 \rho V_{\text {train }}^{2}},
\end{gathered}
$$

where $t$ is the measured time from the passage of the nose of the train with length $L, P(T)$ is the calculated pressure, $P_{0}$ is the undisturbed atmospheric pressure, and $\rho$ is the density of air.

5.1. Effect of Operating Line. The pressure distribution on the inner surface and the vibration law of the steel frame of the SESB are discussed. All the monitoring points are shown in Figure 15, among which $O 1 \sim O 4, C 1 \sim C 4$ are on the steel studs of the open and closed sides, and $D 1 \sim D 5$ are on the top crossbeam. The adjacent point intervals on the same side are all $2.5 \mathrm{~m}$.

5.1.1. Near-Line. Figure 16 describes the dimensionless pressure and acceleration under dimensionless time when the train is running on the near-line. In this part, the analysis focuses on the head pulse and tail pulse that produce the maximum vibrations of the SESB. It can be seen from Figures 16(a) and 16(b) that the peak pressure coefficient $C_{p}$ of positive pressure of head pulse is the largest at $\mathrm{C} 3-\mathrm{C} 4$ at 


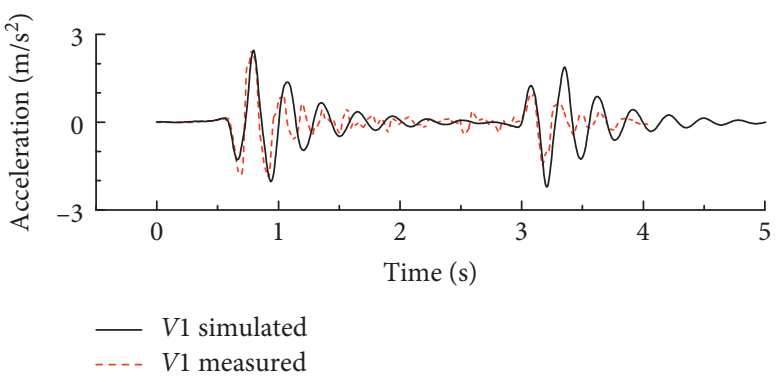

(a)

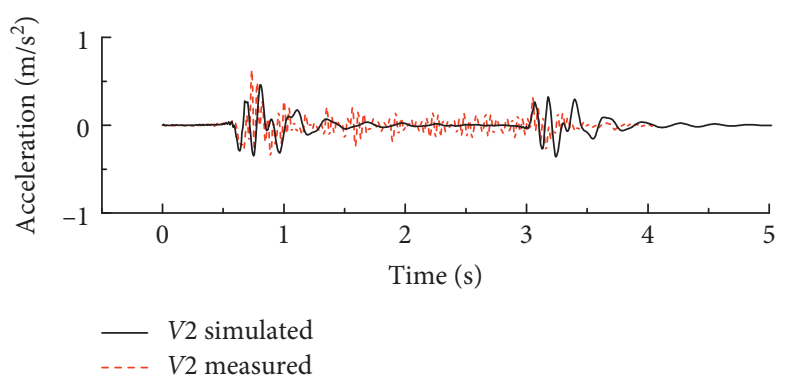

(b)

FIGURE 13: Comparisons of the simulated acceleration time histories with the measured ones.

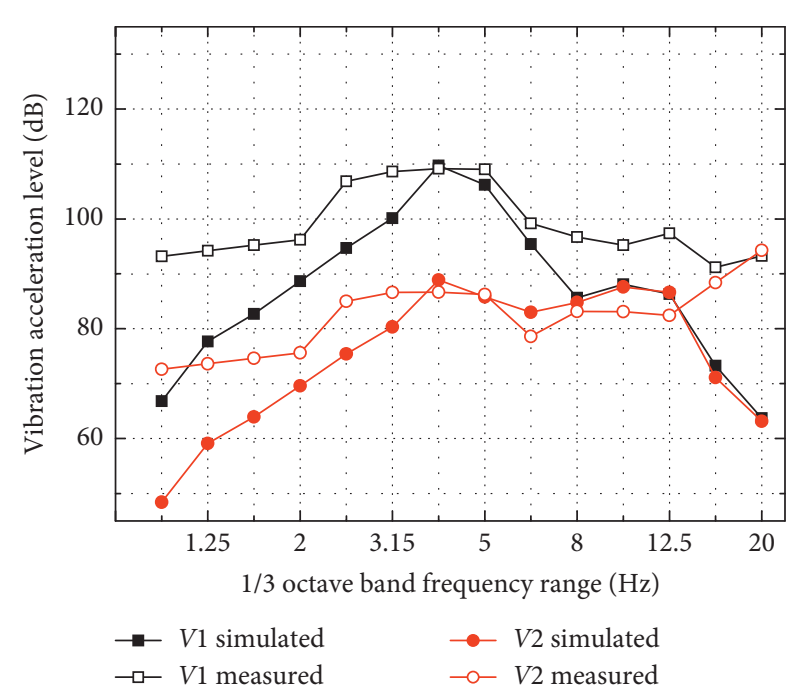

FIgURE 14: Comparisons of the simulated VALs with measured ones.

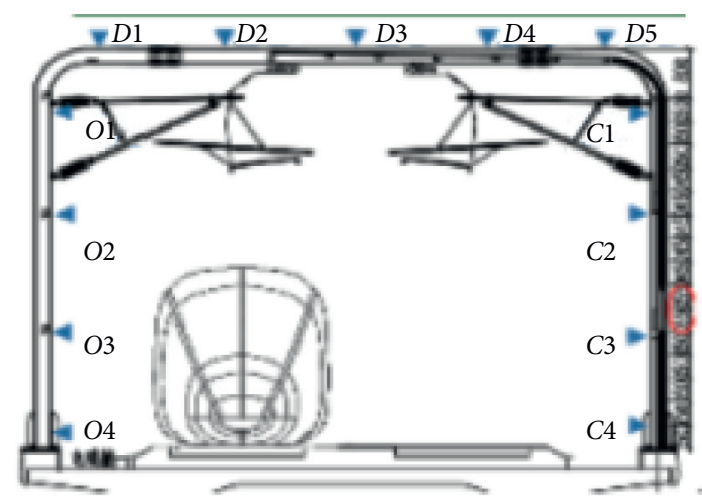

FIGURE 15: Layout of the monitoring points for parameter analysis.

the bottom of the closed side of the SESB, which is 0.137 at $C 4$ and decreases rapidly in the closed side from $C 3$ to 0.071 at $C 1$. At the top of the SESB, the pressure coefficient is only $1 / 3$ compared to that of $C 4$ on the bottom of the closed side and decreases linearly from 0.062 at $D 5$ to 0.041 at $D 3$. The $C_{\mathrm{P}}$ of the negative peak of head pulse, and positive and negative peaks of tail pulse are in the similar cases.
The pressure-induced vibrations at typical location on the steel frame of the SESB are presented in Figures 16(c)16(e). It is obvious that the large vibration of the SESB is mainly triggered both by the head and tail pulse of the pressure. When each pulse reaches to the first small peak value, the vibrations start to increase; when each pulse reaches to the second peak, the vibration reaches to the first peak. The head pulse excites the vibration of the SESB to arrive at the positive acceleration peak, and the tail pulse causes the negative acceleration peak. The absolute value of the former is greater than that of the latter, because the peak pressure of the head pulse is greater than that of the tail pulse. The vibration always lags the pulses, and the maximum vibration happens with the disappearance of the pulses. Then, the SESB periodically attenuates, and the attenuation period of the vibration on top crossbeam is faster than that of the bilateral steel studs. The vibration is not proportional to the fluctuating pressure, and the largest vibrations on both sides of the SESB appear at $\mathrm{Cl}$ and $\mathrm{O} 1$, which have the smallest pressure coefficient, and decrease gradually from top part to the bottom part of the steel studs. Due to the connectivity of top crossbeam, the vibration law on the closed side is similar to that on the open side. The greatest vibration of the top crossbeam locates in the middle D3 point and decreases gradually from $D 3$ in the middle to both ends of the crossbeam.

In order to compare the vibration among all monitored points on SESB, Figure 17 exhibits the peak accelerations and the overall VAL on all points. It can be seen that the distribution of accelerations and VAL are basically the same. The peak vibration acceleration is about $2.3 \mathrm{~m} / \mathrm{s}^{2}$ on both sides and the top of the SESB, which indicates that the sound barrier moves as a whole under the action of fluctuating pressure. As can be seen, for $O 1$ and $C 1$ points on steel studs top, the overall VAL is $115 \mathrm{~dB}$. For measuring points $\mathrm{O} 2 \sim \mathrm{O} 4$ and $C 2 \sim C 4$, vibrations on the upper points are larger than those of lower ones and vibrations on the closed side are larger than those on the open side. It is because the bottom point is close to the fixed end and is subject to greater constraints, while the upper point is far away from the restraint end. For $D 1 \sim D 5$ on top crossbeam, vibration of measuring point $D 3$ at midspan is the most violent, with the overall VAL of $112 \mathrm{~dB}$. Although much lower pressure loading on the top of SESB, D3 point has smaller constraints but subjected to larger dynamic bending moments. 

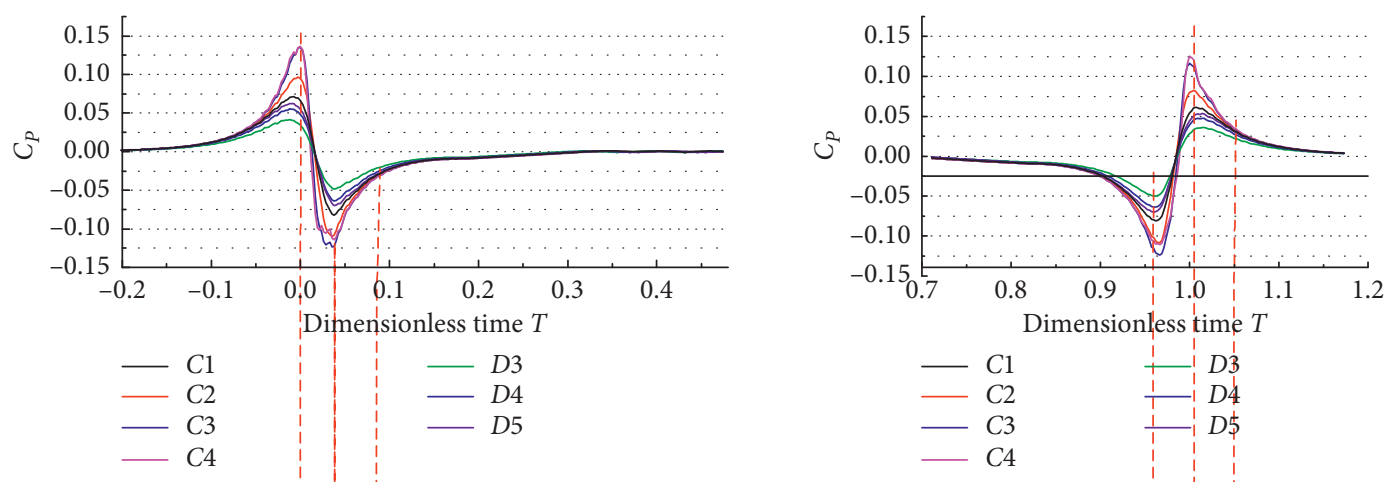

(a)
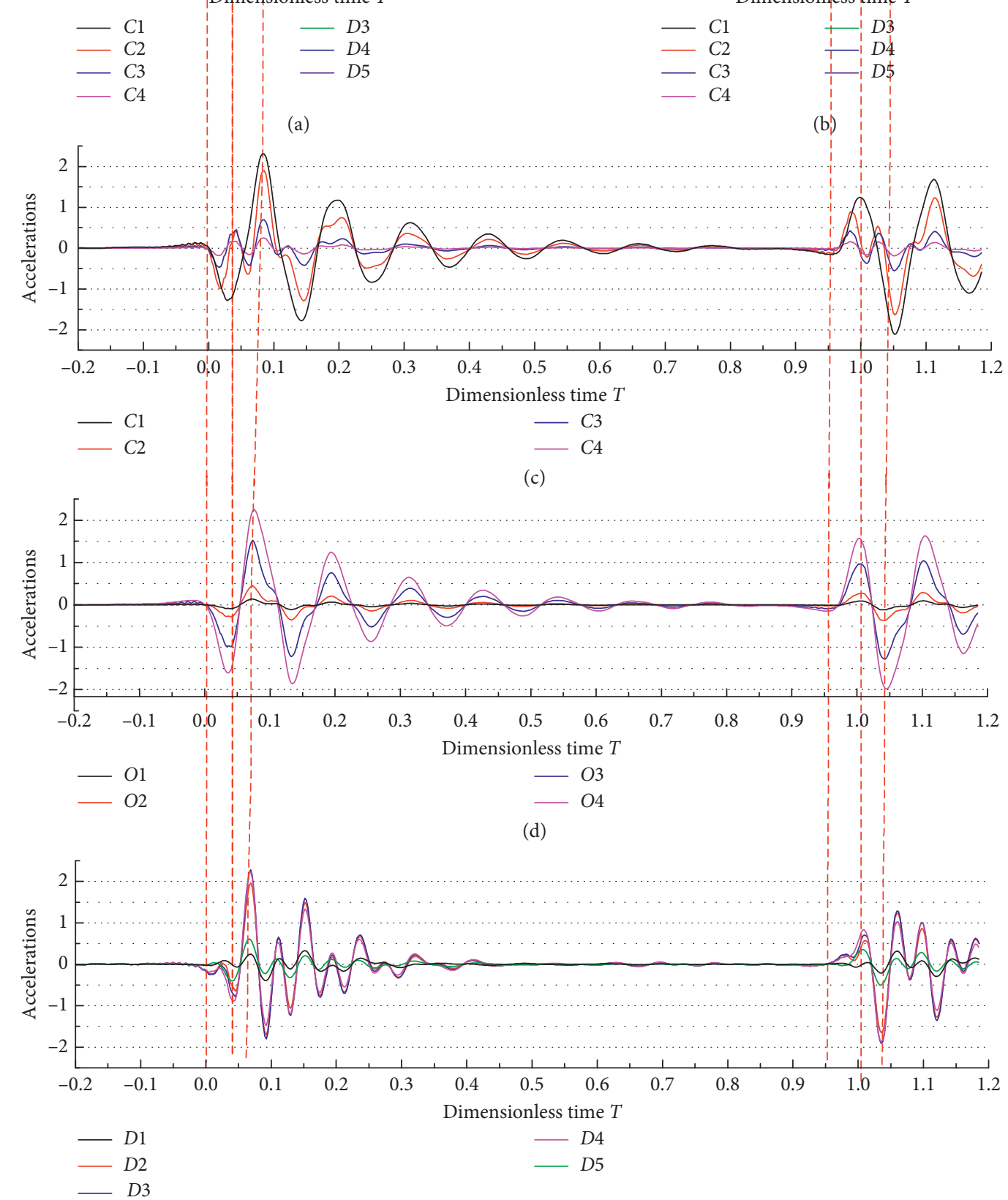

(e)

FIGURE 16: Time histories of the pressure coefficients and peak acceleration under dimensionless time when train on the near-line: (a) head pulse, (b) tail pulse, (c) peak acceleration on the closed side, (d) peak acceleration on the open side, and (e) peak acceleration on the top crossbeam. 


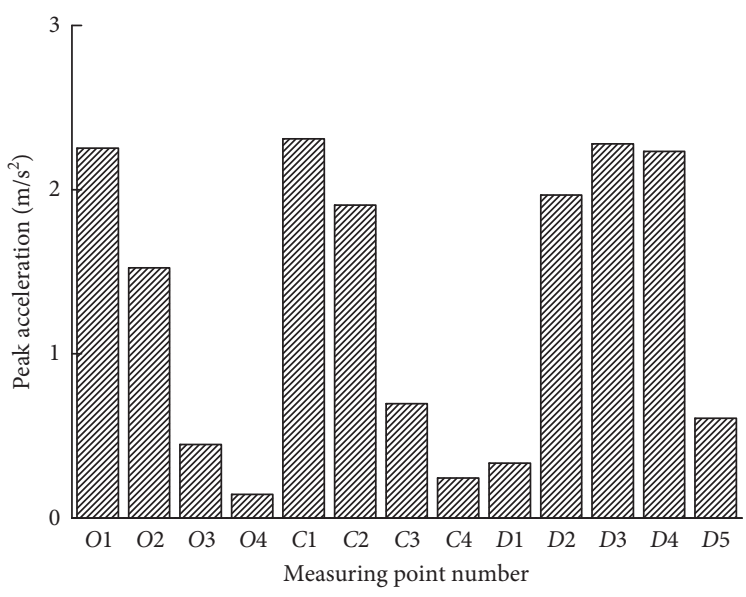

(a)

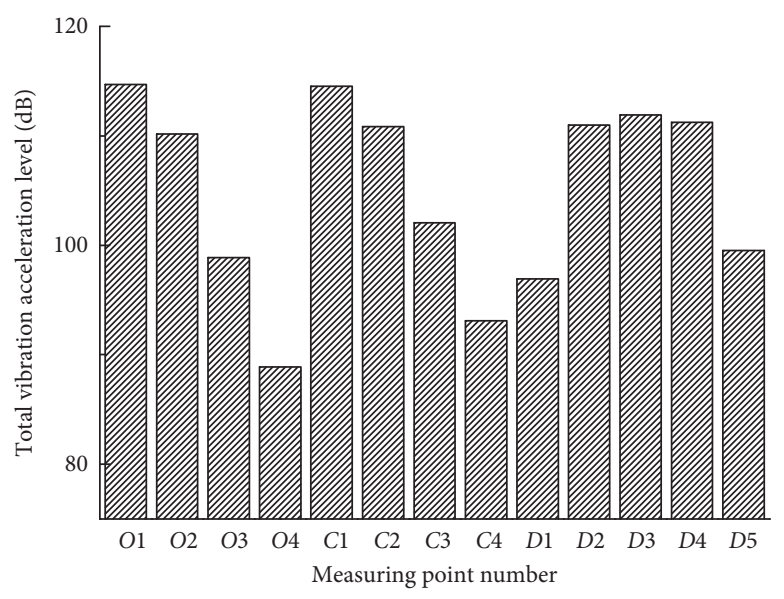

(b)

FIgURE 17: Vibration of SESB: (a) peak acceleration on the steel frame; (b) overall vibration acceleration level on the steel frame.

Vibrations of $D 4$ and $D 5$ are slightly larger than $D 2$ and $D 1$, because the former two points are loaded larger pressure than the latter two points.

5.1.2. Far-Line. The dimensionless pressure on the inner surface of the closed side and vibrations during the train running on far-line are shown in Figure 18. The peak pressure coefficient as described in Figures 18(a) and 18(b) is 0.033 at $C 1$, which is only $1 / 4$ of the value when the train is running on the near-line, and the pressure distributes almost uniformly when the train is on the far-line. Under the action of smaller pressure, the peak vibrations still lag the occurrence of the head and the tail pulse, and the SESB still undergoes periodic attenuation vibration. The vibration periods of both sides are consistent and larger than that of the top crossbeam.

The peak acceleration and overall VAL of the SESB during the far-line operation are illustrated in the Figure 19, and it can be seen that the vibration acceleration and overall VAL in far-line case are far less than those in the near-line case. Although the vibration on both sides is the same, vibrations on the top are greater while the bottom one is less, but the vibration acceleration and total VAL of each measuring point on the open side are greater than those on the symmetrical position on the closed side. It can be seen that for the measuring points $\mathrm{Ol}$ on the top of steel studs on the open side, the peak acceleration is $0.8 \mathrm{~m} / \mathrm{s}^{2}$ and the overall VAL is $105 \mathrm{~dB}$. Also, for measuring points $\mathrm{O} 2 \sim \mathrm{O} 4$ and $C 2 \sim C 4$, vibration on the same height are similar to each other and vibrations of upper points are larger than those of lower ones. For the vibration of top crossbeam, the measuring point $D 3$ located at midspan has the largest vibration with $1.1 \mathrm{~m} / \mathrm{s}^{2}$ peak acceleration and the overall VAL of $108 \mathrm{~dB}$ compared to other points on the crossbeam and even the upper measuring $C 1$ and $O 1$ on studs.

5.2. Effect of Top Plates. The main difference between the SESB and conventional upright sound barrier is whether or not the top of the sound barrier is closed. There are top plates on the SESB. To systematically explore the length effect of top plates on fluctuating pressure and its induced vibration of SESB, seven numerical cases, including sound barriers without any top plates (equivalent to uptight barrier), with only one top corner curve plate, with one top corner curve plate following $1 \sim 5$ top plates ( $1.04 \mathrm{~m}$ wide for each plate), are built and discussed under $350 \mathrm{~km} / \mathrm{h}$ high-speed train operating on the near-line.

5.2.1. Fluctuating Pressure. After calculation, the $C_{P}$ per dimensionless time in different cases is similar to Figures 16(a) and 16(b). According to the calculated results, for all cases with or without the top plates, the greatest fluctuating pressure is still located at the lower part of the steel studs. The peak pressure increases with the extension of the length of total top plates, and the increment in the magnitude of $C_{p}$ is $0.0013 / \mathrm{m}$ for the peak positive pressure mainly loading at the lower part $(C 1-C 2)$ and $0.0014 / \mathrm{m}$ for the peak negative pressure appearing at higher position (plates $P C 2-C 3$ ). The pressures on the $C 1, C 2$, and $C 4$ points were chosen to be analyzed. Table 3 tabulates the peak positive and negative $C_{p}$ on the three points under each case. As can be seen, with the extension length ranging from 1-3 m, $C_{p}$ enlarges severely. While with the extension length range of 3-5 $\mathrm{m}$, the pressure has small increases.

Without any top plates, the peak pressure loading on $C 4$ is approximately 2.5 times larger than that loading on $C 1$, with peak $C_{P}$ of 0.138 and -0.053 , respectively. Compared to pressure of SESB with 6 top plates added to 1 corner curve plate, peak $C_{P}$ on $C 4$ and $C 1$ weakens by about 0.01 and 0.025 , respectively, i.e., the reduction rates are $7 \%$ and $32 \%$. All the top plates of the SESB mitigate the attenuation rate of fluctuating pressure, which makes the SESB subject to greater fluctuating wind pressure.

In all, the top plates confine the size of air circulating area when calculating the fluctuating pressure, which in turn enlarges the pressure on the inner surface of the barrier, and the pressure acting on the SESB is more likely to be enlarged with the increasing extension length of top plates. 

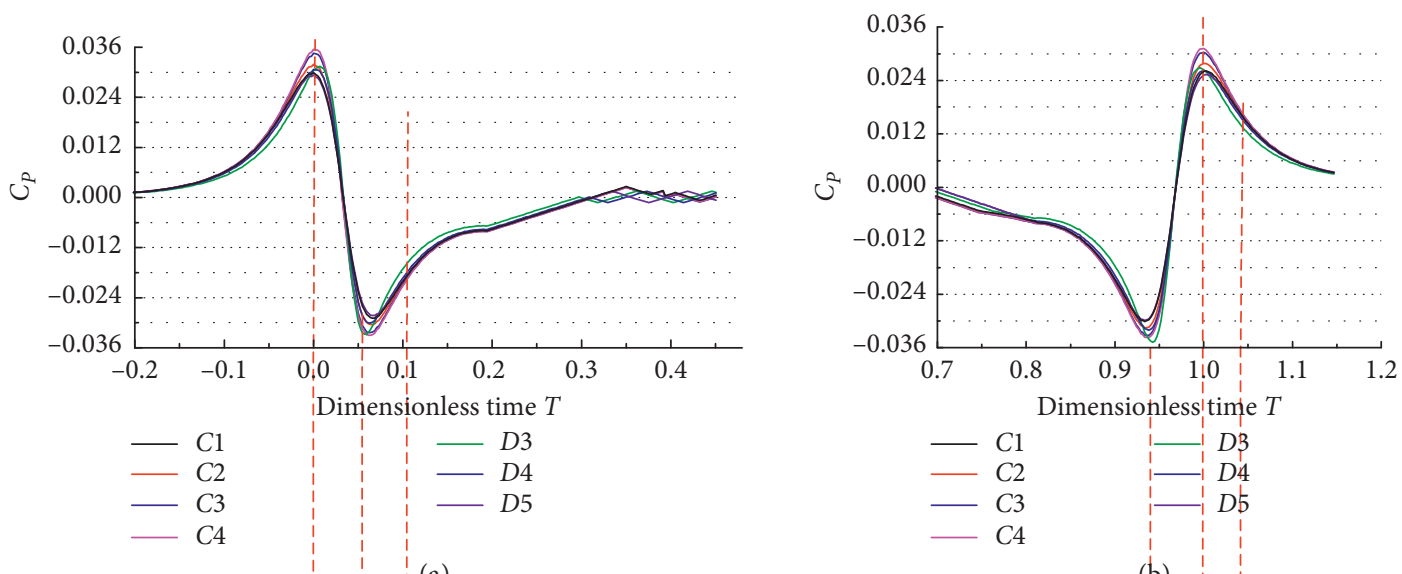

(a)
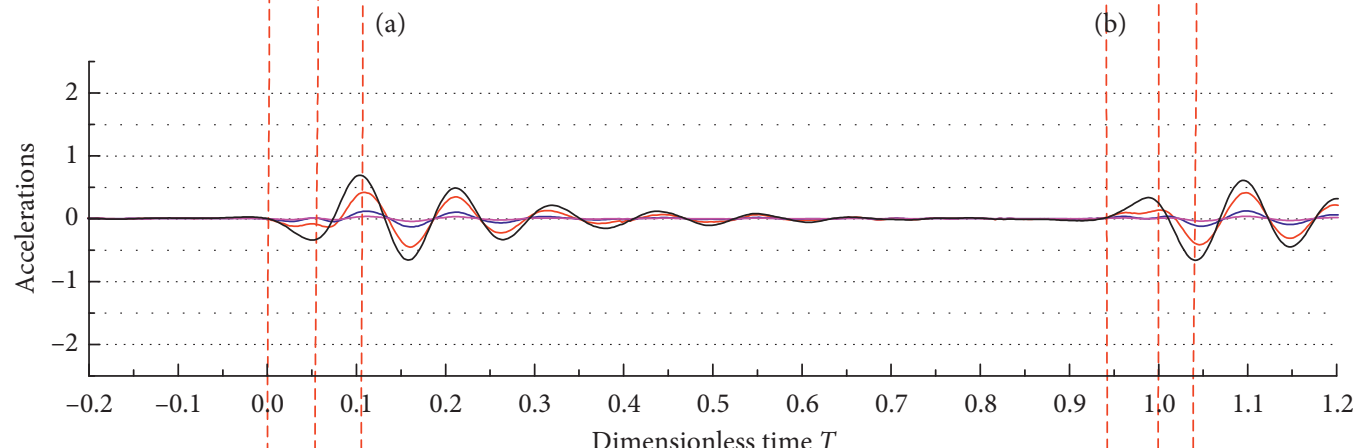

$-\mathrm{Cl}$

$-\mathrm{C} 3$

$-\mathrm{C} 2$

(c)
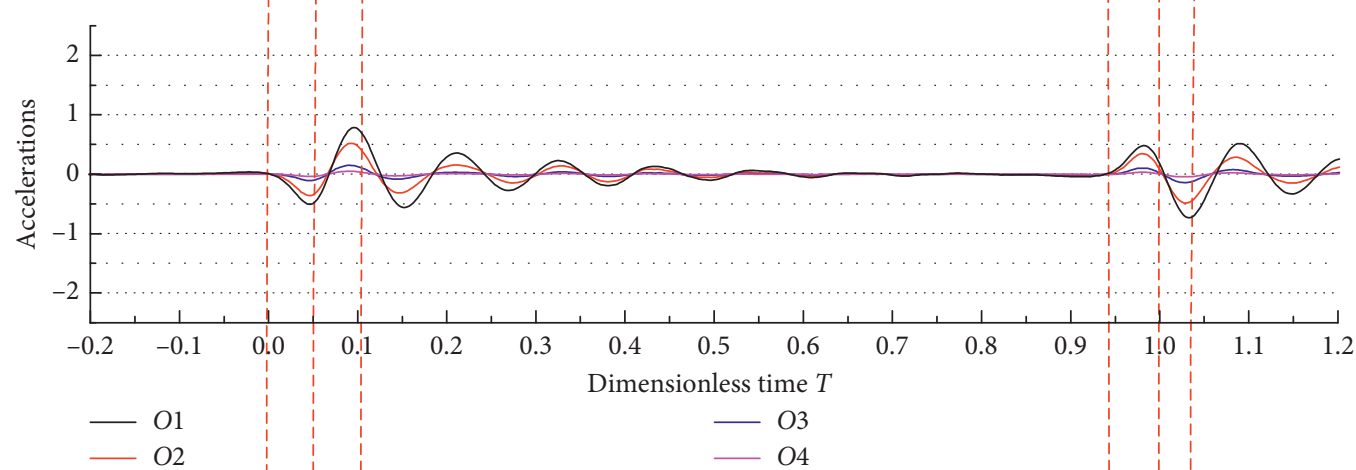

Dimensionless time $T$

$-\mathrm{O} 3$

(d)

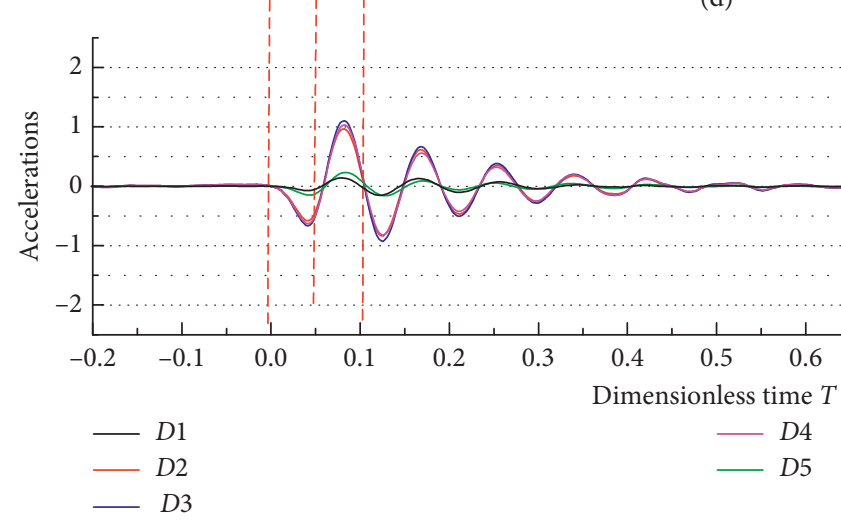

(e)

FIGURE 18: Time histories of the pressure coefficients and peak acceleration under dimensionless time when train on the far-line: (a) head pulse, (b) tail pulse, (c) peak acceleration on the closed side, (d) peak acceleration on the open side, and (e) peak acceleration on the top crossbeam. 


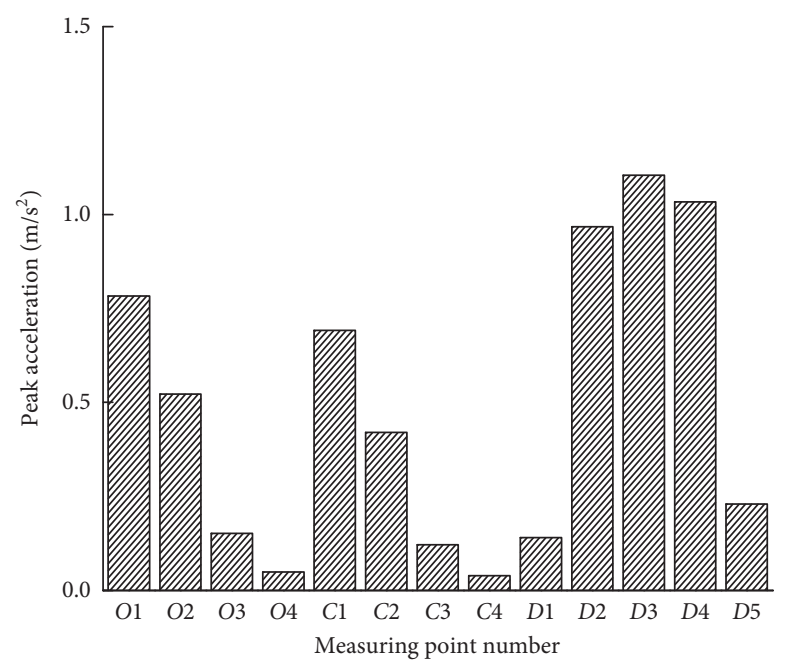

(a)

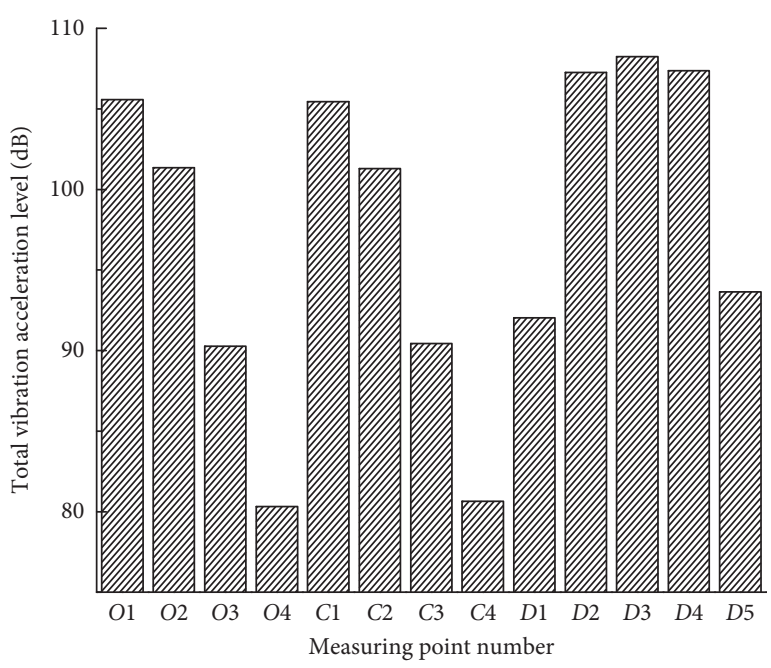

(b)

FIgURE 19: Vibration of SESB: (a) peak acceleration on the steel frame; (b) overall vibration acceleration level on the steel frame.

TABle 3: Peak $C_{P}$ on monitored section of SESB.

\begin{tabular}{lccc}
\hline Working condition & Peak positive $C_{P}$ on $C 4$ & Peak negative $C_{P}$ on $C 2$ & Peak negative $C_{P}$ on $C 1$ \\
\hline No top plates & 0.138 & -0.115 & -0.053 \\
Only curve plate & 0.140 & -0.116 & -0.054 \\
1 top plate & 0.141 & -0.117 & -0.061 \\
2 top plates & 0.143 & -0.119 & -0.068 \\
3 top plates & 0.144 & -0.121 & -0.0712 \\
4 top plates & 0.145 & -0.122 & -0.0738 \\
5 top plates & 0.146 & -0.124 & -0.0759 \\
\hline
\end{tabular}

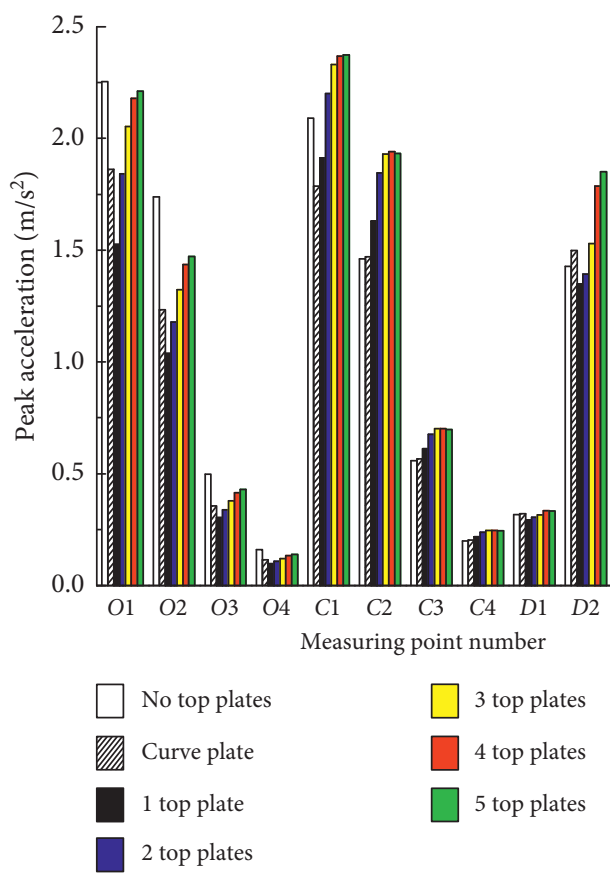

(a)
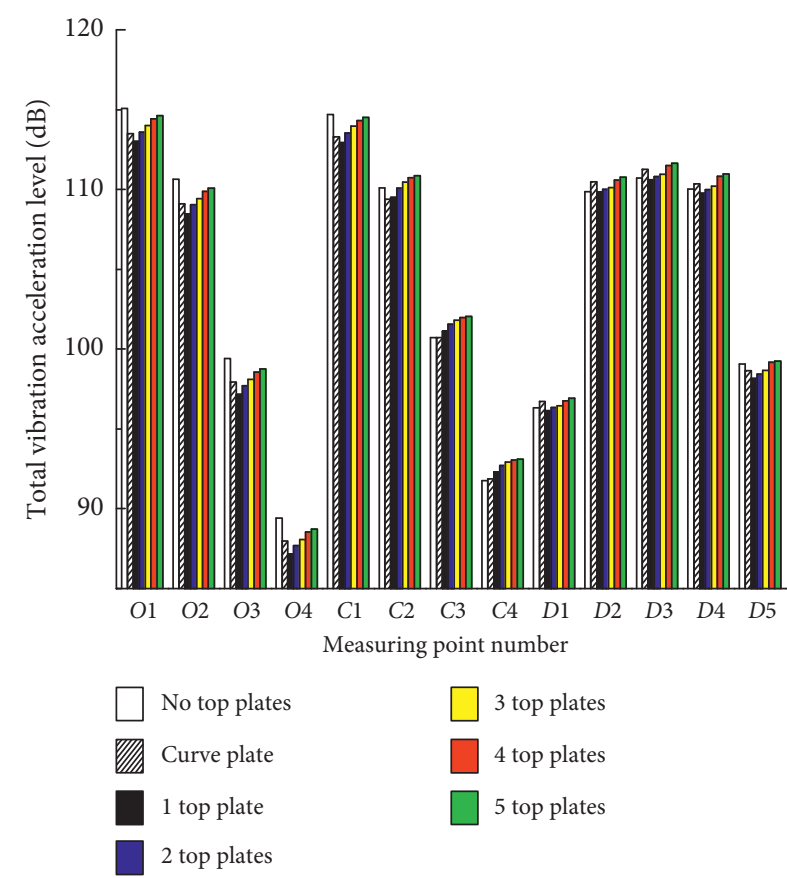

(b)

FIGURE 20: Vibration of SESB with different numbers of top plates: (a) peak acceleration of the steel frame; (b) overall vibration acceleration level of the steel frame. 
5.2.2. Vibration of SESB. To discuss the influence of the top plates on the vibration of SESB, the vibration distributions of above seven cases are shown in Figure 20. As can be seen, when there are no top plates, the peak vibration acceleration of $O 1$ is $2.3 \mathrm{~m} / \mathrm{s}^{2}$, larger than that of $C 1$, about $2.1 \mathrm{~m} / \mathrm{s}^{2}$. As for the overall VAL, there are little difference between $O 1$ and $C 1$ because the top crossbeam can effectively connect the open side and closed side of steel studs. Vibrations of the top crossbeam $(D 1 \sim D 5)$ are relatively smaller compared to the upper parts of steel studs. This is because there is no aerodynamic pressure loading on the barrier top.

For the case with one curve plate and one top plate, compared to the case without top plates, the peak acceleration on $O 1$ is $1.5 \mathrm{~m} / \mathrm{s}^{2}$, attenuates quickly by $35 \%$. This is because the curve plate and the top plate work as connections, connecting adjacent steel frames to the target steel frame and therefore dissipated the vibration. The overall VAL of $O 1$ and $C 1$ is still consistent for the good connectivity of top cross beam.

As for the cases with different numbers of top plates, the train-induced pressure is magnified with the plate number increasing from 1 to 5 , which in turn enlarges the dynamic response of the barrier. The peak acceleration of $O 1$ and $C 1$ per unit extending length of top plates is $0.17\left(\mathrm{~m} / \mathrm{s}^{2}\right)$ and $0.12(\mathrm{~m} /$ $\mathrm{s}^{2}$ ), respectively. For the point $D 3$ at the midspan of crossbeam, the increasing rate of peak vibration is $0.17\left(\mathrm{~m} / \mathrm{s}^{2}\right) / \mathrm{m}$. The increase rate of the overall VAL for measuring points $\mathrm{Ol}, \mathrm{Cl}$, and $D 3$ is about $0.5 \mathrm{~dB} / \mathrm{m}$, which are consistent with each other.

In all, top plates have significant influences on dynamic response under fluctuating pressure loading on SESB. The pressure-induced vibration at the top of both steel studs and the middle of the crossbeam of SESB is the largest and increases with the increase of the number of top plates. Therefore, in addition to paying attention to the noise reduction characteristics of SESBs, it is also necessary to prevent the engineering problems that may be caused by the high-speed train-induced vibration on the upper and top parts.

\section{Conclusions}

In this paper, vibration of the SESB is firstly measured in a in situ test and verified by numerical simulation. A series of studies are then carried out on the dimensionless time, and conclusions could be drawn as follows:

(1) To distinguish the vibration under the fluctuating pressure from original vibration signals according the frequency component of aerodynamic loads, the effect of wheel/rail forces on vibration responses of the SESB could be neglected when analyzing the characteristics of vibration under aerodynamic pressure.

(2) After model calibration through the in-site field test, the presented numerical models are able to reproduce the fluctuating pressure and pressure-induced dynamic responses of the SESB with sufficient accuracy.

(3) When the train is running on the near-line, the largest pressure coefficient is on the bottom part of the closed side of the SESB and decreases gradually with the height of the steel stud, and pressure on top crossbeam also decreases from the closed side to the open side.

(4) Under the action of the head pulse and tail pulse of the fluctuating pressure, the vibration lagging behind will occur and will be periodically attenuated. The vibration laws on both sides of the SESB are the same.

(4) The pressure-induced vibration is the largest on the top of the steel studs and in the middle of crossbeam, and the smallest at the bottom of steel studs.

(5) Top plates have great influences on the fluctuating pressure and the corresponding vibration. The longer is the total length of the top plates, the greater are the pressure and vibration on the inner surface.

\section{Data Availability}

The data used to support the findings of this study are included within the article and available from the corresponding author upon request.

\section{Conflicts of Interest}

The authors declare that they have no conflicts of interest.

\section{Acknowledgments}

This work was funded by the National Natural Science Foundation of China (grant no. 51878565) and the Key Projects of Chongqing Application and Development Plan (no. cstc2014yykfB30003).

\section{References}

[1] X. Zhang, W. Zhai, Z. Chen, and J. Yang, "Characteristic and mechanism of structural acoustic radiation for box girder bridge in urban rail transit," Science of the Total Environment, vol. 627, pp. 1303-1314, 2018.

[2] Q. Li and D. J. Thompson, "Prediction of rail and bridge noise arising from concrete railway viaducts by using a multilayer rail fastener model and a wavenumber domain method," Proceedings of the Institution of Mechanical Engineers, Part F: Journal of Rail and Rapid Transit, vol. 232, no. 5, pp. 13261346, 2018.

[3] L. Song, X. Li, H. Hao, and X. Zhang, "Medium- and highfrequency vibration characteristics of a box-girder by the waveguide finite element method," International Journal of Structural Stability and Dynamics, vol. 18, no. 11, Article ID 1850141, 2018.

[4] N. Zhang, Y. Tian, and H. Xia, "A train-bridge dynamic interaction analysis method and its experimental validation," Engineering, vol. 2, no. 4, pp. 528-536, 2016.

[5] Q. Li, X. Song, and D. Wu, "A 2.5-dimensional method for the prediction of structure-borne low-frequency noise from concrete rail transit bridges," The Journal of the Acoustical Society of America, vol. 135, no. 5, pp. 2718-2726, 2014.

[6] D. J. Thompson, Railway Noise and Vibration: Mechanisms, Modeling and Means of Control, Elsevier, Oxford, UK, 2008. 
[7] H. M. Lee, Z. M. Wang, K. M. Lim, and H. P. Lee, "Investigation of the effects of sample size on sound absorption performance of noise barrier," Applied Acoustics, vol. 157, Article ID 106989, 2020.

[8] X. Zhang, R. Liu, Z. Cao, X. Wang, and X. Li, "Acoustic performance of a semi-closed noise barrier installed on a high-speed railway bridge: measurement and analysis considering actual service conditions," Measurement, vol. 138, pp. 386-399, 2019.

[9] P. A. Morgan, D. C. Hothersall, and S. N. Chandler-Wilde, "Influence of shape and absorbing surface-a numerical study of railway noise barriers," Journal of Sound and Vibration, vol. 217 , no. 3 , pp. $405-417,1998$.

[10] T. Ishizuka and K. Fujiwara, "Performance of noise barriers with various edge shapes and acoustical conditions," Applied Acoustics, vol. 65, no. 2, pp. 125-141, 2004.

[11] S. I. Voropayev, N. C. Ovenden, H. J. S. Fernando, and P. R. Donovan, "Finding optimal geometries for noise barrier tops using scaled experiments," The Journal of the Acoustical Society of America, vol. 141, no. 2, pp. 722-736, 2017.

[12] Z. Wang, L. K. Meng, P. Pracheu, and L. H. Pueh, "Applications of noise barriers with a slanted flat-tip jagged cantilever for noise attenuation on a construction site," Journal of Vibration and Control, vol. 24, no. 22, pp. 5225-5232, 2018.

[13] M. Tokunaga, M. Sogabe, and K. Ono, "Dynamic response evaluation of tall noise barrier on high speed railway structures," Journal of Sound and Vibration, vol. 366, pp. 293-308, 2016.

[14] X.-Z. Santo, X.-H. Liu, D.-J. Liu, and X. Zhang, "Influences of soil-structure interaction on coupled vibration of train-bridge system: theoretical and experimental study," Advances in Structural Engineering, vol. 16, no. 8, pp. 1355-1364, 2013.

[15] T. X. Wu and D. J. Thompson, "Vibration analysis of railway track with multiple wheels on the rail," Journal of Sound and Vibration, vol. 239, no. 1, pp. 69-97, 2001.

[16] Q. Li, K. Wang, S. Cheng, W. Li, and X. D. Song, "Vibration analysis of concrete bridges during a train pass-by using various models," Journal of Physics: Conference Series, vol. 744, Article ID 012140, 2016.

[17] N. Zhang and H. Xia, "Dynamic analysis of coupled vehiclebridge system based on inter-system iteration method," Computers \& Structures, vol. 114-115, pp. 26-34, 2013.

[18] L. Liang, X. Li, J. Yin, D. Wang, W. Gao, and Z. Guo, "Vibration characteristics of damping pad floating slab on the long-span steel truss cable-stayed bridge in urban rail transit," Engineering Structures, vol. 191, pp. 92-103, 2019.

[19] X. Song and Q. Li, "Numerical and experimental study on noise reduction of concrete LRT bridges," Science of The Total Environment, vol. 643, pp. 208-224, 2018.

[20] J. R. Bell, D. Burton, M. C. Thompson, A. H. Herbst, and J. Sheridan, "Moving model analysis of the slipstream and wake of a high-speed train," Journal of Wind Engineering and Industrial Aerodynamics, vol. 136, pp. 127-137, 2015.

[21] Z. Chen, T. Liu, X. Zhou, and J. Niu, "Impact of ambient wind on aerodynamic performance when two trains intersect inside a tunnel," Journal of Wind Engineering and Industrial Aerodynamics, vol. 169, pp. 139-156, 2017.

[22] D. Soper, C. Baker, A. Jackson et al., "Full scale measurements of train underbody flows and track forces," Journal of Wind Engineering and Industrial Aerodynamics, vol. 169, pp. 251264, 2017.

[23] C. Baker, "The flow around high-speed trains," Journal of Wind Engineering and Industrial Aerodynamics, vol. 98, no. 67, pp. 277-298, 2010.
[24] N. Yang, X.-K. Zheng, J. Zhang, S. S. Law, and Q.-S. Yang, "Experimental and numerical studies on aerodynamic loads on an overhead bridge due to passage of high-speed train," Journal of Wind Engineering and Industrial Aerodynamics, vol. 140, pp. 19-33, 2015.

[25] M. Lü, Q. Li, Z. Ning, and Z. Ji, "Study on the aerodynamic load characteristic of noise reduction barrier on high-speed railway," Journal of Wind Engineering and Industrial Aerodynamics, vol. 176, pp. 254-262, 2018.

[26] L. Carassale and M. Marrè Brunenghi, "Dynamic response of trackside structures due to the aerodynamic effects produced by passing trains," Journal of Wind Engineering and Industrial Aerodynamics, vol. 123, pp. 317-324, 2013.

[27] W. J. Luo and H. B. Li, "Dynamic response analysis of noise barrier structures under impulsive wind load," Noise and Vibration Control, vol. 36, no. 2, pp. 162-165, 2016.

[28] T. Zhang, H. Xia, and W. Guo, "Analysis on running safety of train on the bridge considering sudden change of wind load caused by wind barriers," Frontiers of Structural and Civil Engineering, vol. 12, no. 4, pp. 558-567, 2018.

[29] A. Horie and T. Sugiyama, "Field test of train draft on Tohoku Shinkansen," Technical Report A-86, Railway Technical Research pre-Report, Tokyo, Japan, 1986. 